\title{
Patoloji Görüntülerinin Derin Öğrenme Yöntemleri İle Sinıflandırılması
}

\author{
Meral Karakurt ${ }^{1}$, İsmail İşeri ${ }^{2 *}$ \\ ${ }^{1}$ Osmaniye Korkut Ata Üniversitesi, Düziçi Meslek Yüksekokulu, Bilgisayar Teknolojileri Bölümü, Osmaniye, Türkiye, (ORCID: 0000-0001-7318-2798), \\ meralkarakurt@osmaniye.edu.tr \\ 2* Ondokuz Mayıs Üniversitesi, Mühendislik Fakültesi, Bilgisayar Mühendisliği Bölümü, Samsun, Türkiye (ORCID: 0000-0002-0442-1406), \\ ismail.iseri@bil.omu.edu.tr
}

(İlk Geliş Tarihi 17 Ekim 2021 ve Kabul Tarihi 23 Ocak 2022)

(DOI: 10.31590/ejosat.1011091)

ATIF/REFERENCE: Karakurt, M. \& İşeri, İ. (2022). Patoloji Görüntülerinin Derin Öğrenme Yöntemleri İle Sınıflandırılması. Avrupa Bilim ve Teknoloji Dergisi, (33), 192-206.

\section{Öz}

Meme kanseri, kadınlar arasında en çok görülen kanser türüdür. Hastalıkların tespit edilmesi amacıyla kullanılan medikal görüntülerin analiz edilmesi için birçok makine öğrenmesi ve yapay zeka yöntemi kullanılmaktadır. Yapay zeka yöntemlerinden biri olan derin öğrenme, görüntü sınıflandırma, nesne tanıma, segmentasyon gibi işlemler için kullanılmaktadır ve patoloji görüntülerinin analizi için en çok tercih edilen yöntemlerden biridir. Bu çalışmada, derin öğrenme mimarilerinden evrişimsel sinir ağı (CNN) kullanılarak, meme patoloji görüntülerinin sınıflandırması işlemi gerçekleştirilmiştir. Deneyler sonucu elde edilen model ile kanserli ve kanserli olmayan patoloji görüntülerinin sınıflandırılmasında doğruluk değeri 0.8775 , F1 skoru 0.8238 , hassasiyet değeri 0.8381 , hatırlama değeri 0.8762 , MSE değeri 0.1195, MAE değeri 0.2497 elde edilmiştir. Elde edilen yüksek doğruluk, F1 skoru, hassasiyet ve hatırlama değerleri ile düşük hata değerleri, bu çalışma kapsamında önerilen CNN modelinin patoloji görüntülerinin sınıflandırılmasında kullanılabileceğini; özellikle tıp fakültelerinin ve hastanelerin patoloji bölümlerinde kullanılabilir sistemler tasarlanabileceğini göstermektedir.

Anahtar Kelimeler: Patoloji Görüntüleri, Derin Öğrenme, CNN, Sınıflandırma.

\section{Classification Of Pathology Images With Deep Learning Methods}

\begin{abstract}
Breast cancer is the most common type of cancer among women. Many machine learning and artificial intelligence methods are used to analyze medical images used to detect diseases. Deep learning, which is one of the artificial intelligence methods, is used for operations such as image classification, object recognition, segmentation and is one of the most preferred methods for the analysis of pathology images.In this study, classification of breast pathology images was carried out by using a deep learning architecture, Convolutional Neural Networks (CNN). With the model obtained as a result of the experiments, the accuracy value was 0.8775 , the F1 score was 0.8238 , the sensitivity value was 0.8381 , the recall value was 0.8762 , the MSE value was 0.1195 , and the MAE value was 0.2497 in the classification of cancerous and non-cancerous pathology images. The high accuracy, F1 score, sensitivity and recall values and low error values obtained indicate that the CNN model proposed in this study can be used in the classification of pathology images; shows that systems that can be used especially in the pathology departments of medical faculties and hospitals can be designed.
\end{abstract}

Keywords: Pathology Images, Deep Learning, CNN, Classification.

\footnotetext{
* Sorumlu Yazar: Ondokuz Mayıs Üniversitesi, Mühendislik Fakültesi, Bilgisayar Mühendisliği Bölümü, Samsun, Türkiye (ORCID: 0000-00020442-1406), ismail.iseri@bil.omu.edu.tr
} 


\section{Giriş}

Canlıların vücutlarını oluşturan hücreler belli bir düzene göre bölünerek çoğalmaktadır. Kanser, hücrelerin kontrolsüz bir şekilde çoğalmasıdır. Hücrelerin yapısı ve işleyişinin bozulmasına sebep olan kanser, tüm dünyayı ilgilendiren önemli bir sağlık sorunudur. Yanlış beslenme, alkol kullanımı, kimyasal maddeler, obezite, fiziksel aktivite yetersizliği ve daha birçok etken kansere sebep olabilmektedir. Meme kanseri, memeyi oluşturan hücrelerde meydana gelen ve kadınlar arasında en çok görülen kanser türüdür. Dünya Sağlik Örgütü (WHO)'nün verilerine göre 2020'de dünya genelinde 2,3 milyon kadın meme kanserine yakalanmıştır (World Health Organization, 2021).

Medikal görüntü, vücudun iç yapısının çeşitli yöntemler kullanılarak görselleştirilmesi ile elde edilmektedir. Medikal görüntülerin bilgisayar ortamına aktarılmasıyla beraber bilgisayar destekli analizler yapmak amacıyla birçok uygulama geliştirilmektedir. Çeşitli matematiksel işlemlerle mevcut verilerden bilgi edinen ve bu bilgiler ile tahminler yapabilen yöntemler bütününe makine öğrenmesi denir (Rende vd, 2017). Bir makine öğrenmesi yöntemi olan yapay sinir ağları, yapay sinir hücresi denilen nöronlar kullanılarak tahmin ve sınıflandırma gibi belli amaçlara ulaşmayı amaçlayan bir bilim dalıdır. Medikal görüntü analizi işlemleri, 1970'li yıllardan 1990'lı yıllara kadar kural tabanlı sistemler olan uzman sistemler kullanılarak kenar filtreleme gibi düşük seviyeli piksel işlemleri ile gerçekleştirilmiştir. 1990'l1 yılların sonunda eğitim verilerinin bir sistem geliştirmek için kullanıldığı denetimli sistemler popüler olmuştur (Litjens vd, 2017).

Segmentasyon, öznitelik çıkarımı ve istatistiksel sınıflandırıcıların kullanıldığı makine öğrenmesi yaklaşımları, günümüzde yaygın olarak kullanılan yapay zeka temelli medikal görüntü analiz sistemlerinin temelini oluşturmaktadır. $\mathrm{Bu}$ sistemlerin tasarımında, öznitelik çıkarımı ve çıkarılan özniteliklerin bilgisayarın öğrenmesini sağlamak önemlidir. Öznitelik çıkarımı yapmak amacıyla, temel bileşen analizi (principal component analysis - PCA), görüntü parçalarının kümelenmesi ve daha birçok metot kullanılmaktadır (Litjens vd, 2017; Özcan, 2014).

Geleneksel makine öğrenmesi yöntemlerinden farklı olarak öznitelik çıkarımının mimari tarafından yapılması amacıyla geliştirilen derin öğrenme mimarileri, giriş verilerini çıkışlara dönüştüren birçok katmandan oluşan yapay sinir ağlarıdır. Bu mimarilerde, her katmanda probleme ait bazı öznitelikler öğrenilerek bu öznitelikler bir üst katmana girdi verisi olarak verilmektedir (Işık ve Artuner, 2016). Böylece, en alt katmandan en üst katmana doğru detayları giderek artan özniteliklerin öğrenildiği bir yapı oluşturulmaktadır. Son yıllarda, verilerden özellik çıkarımının doğrusal olmayan biçimde ve hızlı yapılması, kendi kendine öğrenme ve genelleme kabiliyeti derin öğrenme yöntemlerine olan ilgiyi arttırmaktadır. Derin mimariler daha az bellek alanı gerektirmekte, daha hızlı işlemler yapmakta ve daha verimli sonuçlar sağlamaktadır. Görüntü işleme, sinyal işleme, doğal dil işleme, ilaç keşfi ve daha birçok alanda derin öğrenme yöntemleri başarıyla kullanılmaktadır (Carrio vd, 2017; Chen vd, 2018; Ekmekji, 2016; Vargas vd, 2017; Xie vd, 2017).

Görüntü analizi işlemlerinde günümüze kadar en çok başarı gösteren derin öğrenme mimarileri, evrişimsel sinir ağlarıdır (Convolutional Neural Networks, CNN) (Litjens vd, 2017). CNN mimarileri, 1980'li yıllarda ortaya atılmıştır ve 1995 'te medikal görüntü analizi işlemleri için kullanılmaya başlanmıştır (LeCun vd, 1989). İlk başarılı CNN mimarisi olan LeNet, 1998 yılında, el yazısı rakam tanımada kullanılmıştır (LeCun vd, 1998). Bu başarılarına rağmen CNN mimarilerinin kullanımı, yazılım ve donanım eksiklikleri sebebiyle 2010'lu y1llara kadar popülerlik kazanamamıştır. 2012'de ortaya atılan ve CNN mimarileri için dönüm noktası olan AlexNet mimarisi, derin sinir ağları konusunda bir standartlaştırma yarışması olan ImageNet yarışmasında \%83.6 başarıyla birinci olmuştur (Krizhevsky vd, 2012). AlexNet' in bu başarısı sonraki yıllarda yapılan ImageNet yarışmasında derin öğrenme kullanımının önemli derecede artmasını sağlamıştır (Komura ve Ishikawa, 2018). AlexNet mimarisinin LeNet mimarisi ile benzerlikleri vardır. Ancak AlexNet mimarisinde hiperbolik tanjant aktivasyon fonksiyonu yerine ReLU kullanılması, günümüzde en çok tercih edilen mimarilerden biri olmasını sağlamıştır (Krizhevsky vd, 2012). 2013 y1lında ZFNet mimarisi \%88.3 başarıyla ve 2014 yılında GoogleNet mimarisi \%93.3 başarıyla ImageNet yarışmasını kazanmışlardır. 2014 yılında tanıtılan ve 22 katmanlı olan GoogleNet verimlilik ve pratikliğiyle düşük bellekli ve sınırlı hesaplama kaynaklarına sahip olanlar dahil tüm cihazlarda kullanılmak amacıyla tasarlanmıştır (Szegedy vd, 2015). 2015 y1lında ise ResNet mimarisi, \%3.57 hata oranı ile ImageNet yarışmasında birinci olmuştur. 2015 yılında ayrıca, SegNet ve UNet derin mimarileri de tanıtılmıştır (Lee vd, 2017).

Derin öğrenme yöntemleri kullanılarak yapılan birçok çalışma vardır. Örneğin, Lo S. vd., genel olarak medikal görüntülerde örüntüleri tanımak amacıyla $\mathrm{CNN}$ mimarisini kullanmışlardır. Göğüs radyografileri üzerinde akciğer nodüllerininin tespiti ve mamografi görüntülerinde mikro kireçlenme tespiti yapmak için CNN mimarisini test etmişlerdir. İki gizli katman kullanarak tasarlardıkları ağın performans değerlendirmesi için ROC eğrisini kullanmışlardır ve ağın başarılı sonuçlar ürettiğini ve klinik ortamlarda kullanılabileceğini göstermişlerdir (Lo vd, 1995). Cireşan D.C. vd., meme histoloji görüntülerinde mitozu saptamak için derin sinir ağlarını kullanmışlardır. Uluslararası Üretim Araştırma Konferansı (International Conference on Production Research - ICPR) 2012 mitoz tespit yarışmasını kazanarak, diğer yarışmacıları üstün bir farkla geride bırakmışlardır (Cireşan vd, 2013). Davy A. vd., beyin tümörü tanısı koymak amacıyla beyin tümörü görüntüleri üzerinde derin sinir ağlarını kullanmışlardır. Bu çalışma, 2013 yılında yapılan beyin tümörü görüntü segmentasyonu yarışmasında (BRATS2013) en başarılı çalışma olarak seçilmiştir (Davy vd, 2014). Aynı amaçla Havaei M. vd., bir CNN çıktısının sonraki bir CNN için ek bilgi kaynağı olarak kullanıldığı bir kaskad CNN mimarisi kullanmışlardır. Mimarilerini test etmek amacıyla, BRATS2013 test veri setini kullanarak mimarilerinin o dönemde yayınlanmış olan son teknolojilere göre daha iyi bir gelişme gösterdiğini ve 30 kat daha hızlı olduğunu göstermişlerdir (Havaei vd, 2017). Zhao X. vd. de tamamen bağl1 evrişimsel sinir ağları (Fully Convolutional Neural Networks - FCNNs) ve koşullu rastgele alanlarını (Conditional Random Fields - CRF) birleştirdikleri bir mimari sunmuşlardır (Zhao vd, 2018). Danaee P. vd., meme kanseri tanıma ve segmentasyonunda genlerin kritik olarak tespiti için derin öğrenme kullanmışlardır. Yüksek boyutlu ve gürültülü gen verilerinden öznitelik çıkarmak için 4 katmanlı bir yığın gürültü azaltan otomatik kodlayıcı (Stacked Denoising Auto Encoder - SDAE) ve SDAE' nin öğrenme aşamasında ezberlemeyi engellemek için de seyreltme hiper-parametresini kullanmışlardır (Danaee vd, 2016). Isin A. ve Özdalili S., Elektrokardiyogram (EKG) görüntülerini sinıflandırmada AlexNet mimarisini kullanmışlardır. Eğitim verilerinde \% 98,51 
ve test verilerinde \% 92 civarında doğruluk değerleri elde etmişlerdir (Isin ve Özdalili, 2017). Xiao K. vd., histopatolojik görüntülerdeki lenf düğümlerinde meme kanseri metastazlarının tespiti ve sınıflandırılması için ResNext mimarisini kullanmışlardır. 101 katmanlı CNN ile büyük bir veri setini parça tabanlı olarak eğitmişlerdir. Sınıflama performansını değerlendirmek için CAMELYON 2017'de kabul edilen 5 sınıflı 2. derece ağırlıklı kappa metriği kullanmışlardır. Meme kanseri metastazlarını 2 sınıfa ve 3 sınıfa ayımışlardır. Kappa metriğini, 5-kat çapraz doğrulama ile 3 sınıfa ayırmada \%99.54 ve 2 sinıfa ayırmada \%89.57 başarılı olarak ölçmüşlerdir (Xiao vd, 2017). Nirschl J.J. vd., akut kalp yetmezliği tanısı koymak amacıyla, H\&E boyalı kardiyak histopatoloji görüntüleri üzerinde Caffe kütüphanesi ile beraber CIFAR-10 yarışmasında kullanılan AlexNet mimarisini değiştirerek kullanmışlardır. Diğer taraftan el yapımı özellikleri ile birlikte rastgele orman sınıflandırıcı kullanarak yaptıkları karşılaştırma neticesinde derin öğrenme yönteminin daha başarılı olduğunu göstermişlerdir (Nirschl vd, 2017). CAMELYON16 (Kasim 2015- Kasim 2016) meme kanseri olan kadın hastalarda lenf düğümü metastazlarının tespiti yarışmasında, bazı derin öğrenme algoritmaları 11 patologdan daha iyi performans göstermişlerdir. Yarışmada sunulan 32 algoritmadan 25 tanesi derinlemesine evrişimsel sinir ağları kullanmışlardır (Bejnordi vd, 2017). Motlagh N.H. vd., meme kanseri alt tiplerini sınıflandırmak amacıyla bir derin öğrenme çalışması yapmışlardır. Mimarilerinin ilk adımı olarak önceden eğitilmiş bir ResNet V1 50 mimarisi kullanarak meme kanseri ile beraber mesane, akciğer ve lenfoma kanserlerinin tanısında ortalama \% 99.8' lik bir doğruluk elde etmişlerdir. İkinci adımda ise bir ResNet V1 152 mimarisi kullanarak \% 98.7 doğrulukla iyi huylu ve kötü huylu meme kanserlerini sınıflandırmışlardır (Motlagh vd, 2018). Roy K. vd., histopatolojik meme görüntülerini sınıflandırmak amacıyla $\mathrm{CNN}$ kullanan yama tabanlı bir sınıflandırıcı önermişlerdir. Görüntü sayısının yetersizliğinden dolayı, yamaların çıkarılması ve büyütülmesi ile gerçekleştirdikleri sınıflandırma işlemi \%87 hassasiyet sağlamıştır (Roy vd, 2019). İlkılıç Aytaç Z. vd., tiroid kanseri tespiti yapmak amacıyla evrişimsel sinir ağlarını kullanmışlardır. Elde ettikleri başarılı test sonuçları ile önerdikleri modelin tiroid kanseri tespitinde kullanılabileceklerini göstermişlerdir (İlkılıç Aytaç vd, 2021). Özçelik Y.B. ve Altan A., diyabetik retinopati tespiti yapmak için evrişimsel sinir ağları ve transfer öğrenmesi yöntemlerini kullanmışlardır. Önerdikleri modelin \% 97.8 sınıflandırma performansına sahip olduğunu göstermişlerdir (Özçelik ve Altan, 2021).

Bu çalışmada, meme kanserinin yüksek doğruluk ve hızda tespit edilmesi amacıyla bir CNN modeli önerilmektedir. İkinci bölümde modelin geliştirilmesinde kullanılan materyal ve metot anlatılmaktadır. Üçüncü bölümde modelin eğitim ve test işlemleri yapılmakta ve deneysel sonuçlar tartışılmaktadır. Son bölümde ise çalışmanın sonuçları ve gelecekte kullanılabileceği bilgileri verilmektedir.

\section{Materyal ve Metot}

$\mathrm{Bu}$ çalışmanın uygulama akış diyagramı Şekil 1 ile gösterilmiştir.

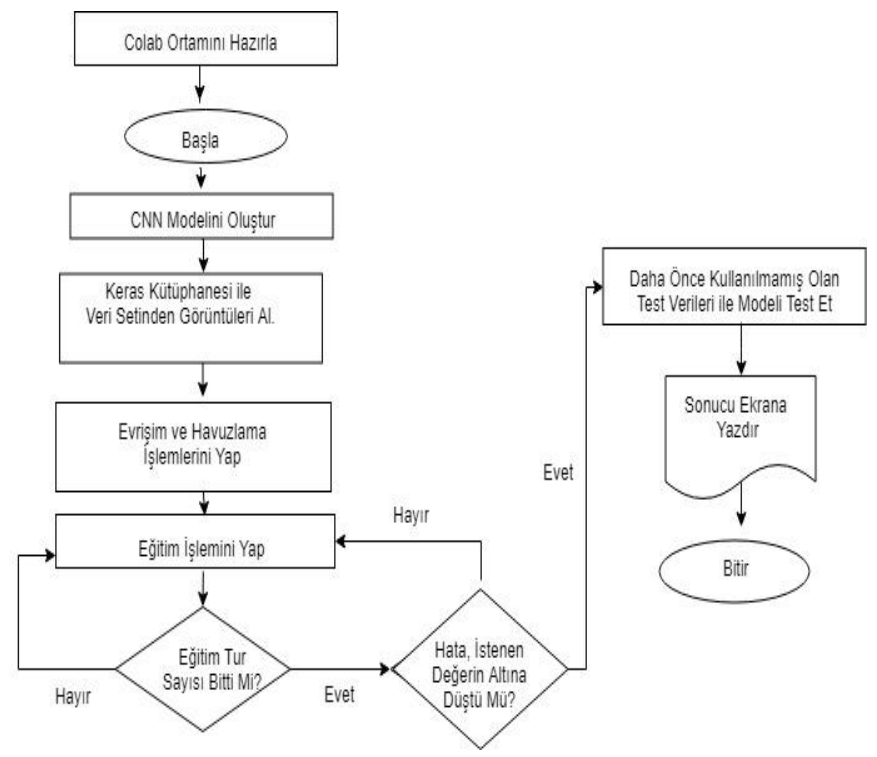

Şekil 1. Uygulama Akış Diyagramı (Figure 1. Application Flow Diagram)

\subsection{Patoloji Veri Seti}

Eski Yunancada hastalık bilimi anlamına gelen patoloji, tıpta bir uzmanlık alanıdır. Patotojik görüntüleme, hastalıklı organların çıplak gözle veya mikroskop altındaki anormal görünümlerinin incelenmesi amacıyla ortaya atılan görüntüleme tekniğidir. Mikroskop altında cam slaytlar kullanılarak yapılan patolojik görüntülemenin yerini günümüzde dijital görüntüleme almıştır. Dijital patoloji görüntüleri, bir bilgisayar ekranında veya mobil aygıtta görüntülenebilen yüksek çözünürlüklü dijital görüntüler sağlamak amacıyla bir tarama aygıtı kullanılarak cam slaytların taranmasıyla elde edilmektedir. İncelenecek dokular özel makinelerle taranmakta ve bilgisayar ortamına dijital görüntüler olarak aktarılmaktadır (Veta vd, 2014). Anatomi ve fizyolojide öğrenilen bilgilere, patolojik görüntülerin eklenmesiyle hastalıkların daha kolay anlaşılması hedeflenmiştir. Günümüzde, tümörlerin tanısı başta olmak üzere, pekçok hastalığın kesin tanısı için patolojik inceleme gereklidir.

Hastadan alınan biyopsi örneklerinin görüntülenmesinde yaygın olarak hematoksilin ve eosin (H\&E) boyama tekniği kullanılmakta ve çekirdek, stoplazma gibi yapıların farklı renkler alarak belirginleştirilmesi sağlanmaktadır (Basavanhally, 2010; Basavanhally vd, 2011; Belsare ve Mushrif, 2012; Cosatto vd, 2008; Dinsmore, 2014; Glotsos vd, 2004; Madabhushi ve Lee, 2016; Nedzved vd, 2007; Paramanandam vd, 2016).

Tüm slayt görüntüleme (WSI) teknolojisinin kullanılmasıyla normal patolojiden daha başarılı sonuçlar elde edilmekte ve görüntülerin yorumlanması ve ağ ortamında paylaşımı kolaylaşmaktadır (Pantanowitz, 2010; Rani ve Amsini, 2018).

$\mathrm{Bu}$ çalışmada kullanılan meme patoloji örneklerine bakıldığında Şekil 2(a)'da gösterildiği gibi kanserli olmayan meme patoloji görüntülerinde çekirdek, sitoplazma ve diğer dokuların yapısı ve işleyişleri belli bir düzende iken Şekil 2(b) ile gösterilen kanserli hücrelerde çekirdeklerin rastgele bölünerek çoğaldıkları ve sitoplazmanın yapısını da bozdukları görülmektedir. Bu bozulmalar veri setinin bazı görüntülerinde net olarak gözle görülebilirken bazı görüntülerde net olarak görülememektedir. 


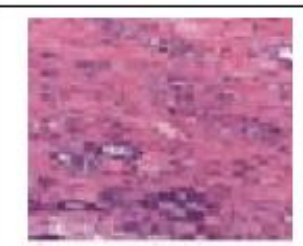

(a)

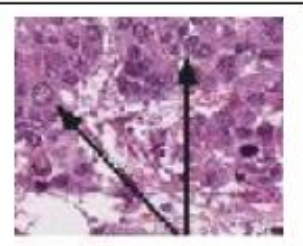

(b)
Şekil 2. (a) Kanserli Olmayan Meme Patoloji Görüntüsü ve (b)Kanserli Meme Patoloji Görüntüsü (Figure 2. (a) Pathology Image of Non-Cancerous Breast and (b) Cancerous Breast Pathology Image)

Bu çalışmada, Kaggle web sitesinde Paul Mooney tarafindan 2017 yılında sunulan meme patoloji görüntülerinden oluşan bir veri seti kullanılmıştır. Bu veri setinden eşit sayıda kanserli ve kanserli olmayan 60000 görüntü alınarak bu mimarinin eğitim ve test işlemlerinde kullanılmıştır. Bir mimarinin tasarlanmasında kullanılacak veri setinin büyüklüğü, dağılımının belli bir oranda olması mimarinin başarısında büyük önem taşımaktadır. Bu sebeple, bu mimaride kullanılan veri seti eşit dağılımlı olarak ayarlanmıştır.

$\mathrm{Bu}$ veri setindeki 50x48, 45x48 gibi farklı boyuttaki görüntüler yeniden boyutlandırılmış ve elde edilen $50 \times 50$ boyutlu görüntüler üzerinde sınıflandırma işlemi gerçekleştirilmiştir. Bu görüntülerin 40000 tanesi eğitim amacıyla 20000 tanesi de test amacıyla kullanılmıştır. Eğitim ve test verileri eşit sayıda kanserli ve normal görüntüler içermektedir.

\subsection{Evrişimsel Sinir Ağları (CNN)}

Görüntü analizi işlemlerinde en yaygın kullanım alanına sahip derin öğrenme mimarisi olan CNN'ler, bir veya birden fazla evrişim katmanından oluşan ve bu katmanlarda doğrusal olmayan fonksiyonların bulunduğu yapılardır. Genel olarak bir CNN mimarisi; sırasıyla girdi, evrişim, havuzlama, aktivasyon ve sınıflama katmanlarından oluşmaktadır.

Diğer makine öğrenmesi yöntemlerinden farklı olarak derin öğrenme mimarilerinde, özellik çıkarımı ham veriler üzerinde yapılmakta ve bu veriler işlenirken gerekli bilgiler, farklı katmanlarda oluşturulmuş temsillerle elde edilmektedir. Ayrıca derin öğrenme mimarilerinde çok yüksek miktarda veriyi işleyebilecek çok yüksek hesaplama gücü olan donanımlara ihtiyaç duyulmaktadır.

Aynı boyutta katmanlara sahip standart ileri beslemeli sinir ağları ile karşılaştırıldığında, CNN' ler çok daha az bağlantı ve parametreye sahiptir; bu sayede eğitilmesi daha kolaydır (Krizhevsky vd, 2012).

$\mathrm{Bu}$ çalışmada kullanılan CNN mimarisi Şekil 3'te gösterildiği gibi özellik çıkarımı aşamasında 3 tane evrişim katmanı, 3 tane ReLU katmanı ve 3 tane havuzlama katmanı kullanılarak görüntü boyutları küçültülmüş ve bu görüntülerden anlamlı bilgilerin çıkarılması sağlanmıştır. Daha sonra, çıkarılan bu özellikler tek boyutlu vektör olarak düzleştirilmiş 200 nörona sahip bir tam bağlı katman ile sınıflandırılmıştır.

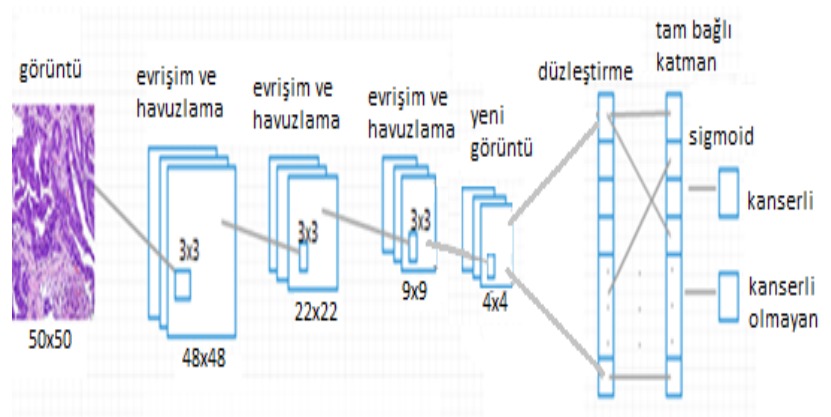

Şekil 3. Bu Çalışmada Kullanılan CNN Mimarisi (Figure 3. CNN Architecture Used in This Study)

Meme patoloji görüntüleri üzerinde evrişim işlemleri yapılarak bu görüntülerden anlamlı bilgiler elde edilmiştir. Her evrişim işleminden sonra maksimum havuzlama işlemi yapılarak bilgi kaybını en az oranda tutacak şekilde görüntülerin boyutları küçültülmüştür. Ağın başarısını ölçmek amacıyla 1 değerine yakınsaması istenen F1 skoru, doğruluk (accuracy), hassasiyet (sensitivty) ve hatırlama (recall) metrikleri ile 0 değerine yakınsaması istenen MSE ve MAE metrikleri kullanılmıştır.

Evrişim katmanında, girdi verilerinden öznitelik haritası üretilmiştir Evrişim işlemi, bir filtrenin tüm görüntü üzerinde piksel piksel kayarak bir nokta çarpım yapılmasıdır. Şekil 4 ile gösterilen $3 \times 3$ boyutlu örnek bir filtre kullanılarak $4 \times 4$ boyutlu örnek bir görüntü üzerinde evrişim işlemi yapılarak $2 \times 2$ boyutlu bir görüntü elde edildiği gösterilmiştir. Burada önemli olan bir husus, farklı cihazlarla elde edilen yüksek çözünürlüklü orijinal görüntülerin derin öğrenme mimarilerinde kullanılabilecek boyutlara dönüştürülmesinde belli bir standardın olmamasıdır (Komura ve Ishikawa, 2018).

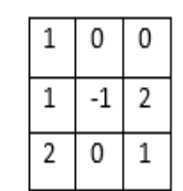

$3 \times 3$ boyutlu filtre

\begin{tabular}{|l|l|l|l|}
\hline $2_{\mathrm{x} 1}$ & $1_{\mathrm{x} 0}$ & $3_{\mathrm{x} 0}$ & 0 \\
\hline $1_{\mathrm{x} 1}$ & $1_{\mathrm{x}(-1)}$ & $0_{\mathrm{x} 1}$ & 0 \\
\hline $3 \mathrm{x}_{2}$ & $1_{\mathrm{x} 0}$ & $0_{\mathrm{x} 1}$ & 1 \\
\hline 0 & 2 & 2 & 1 \\
\hline
\end{tabular}

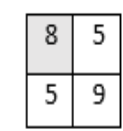

elde edilen çiłaş görüntüsü
Şekil 4. Örnek Filtrenin Örnek Görüntüye Uygulanması (Figure 4. Applying the Sample Filter to the Sample Image)

Havuzlama katmanında, sonraki katmana geçen değerlerin en büyükleri, en küçükleri ya da ortalamaları alınarak bir alt örnekleme işlemi yapılmaktadır.

Bu çalışmada, Şekil 5' te gösterildiği gibi son katmana geçen değerlerin en büyüklerini alma işlemi olan maksimum havuzlama işlemi kaydırma (stride) değeri 1 ve filtre boyutu 2x2 seçilerek gerçekleştirilmiştir. Havuzlama işleminin sonucunda, çıkış görüntüsünün filtre boyutu, kaydırma ve dolgulama (padding) parametrelerinin değerlerine göre küçülmektedir. Seçilen hiperparametrelerle ilişkili olarak evrişim ve havuzlama katmanlarında boyut azaltma işlemi aşağıda matematiksel denklemlerle ifade edilmektedir. $n \times n$ boyutlu bir giriş görüntüsü üzerinde, $f x f$ boyutlu bir özellik çıkarıcı filtre ve $s$ kaydırma adımı hiperparametreleri kullanılarak $p$ ile ifade edilen dolgulama işlemi; $p=(f-1) / 2$ formülü ve çıktı görüntüsünün boyutu $m \times m$ olmak 
üzere; $\quad m=[(n+2 p-f \quad-s]+1$ formülü kullanılarak hesaplanmaktadir (Kurt, 2018).

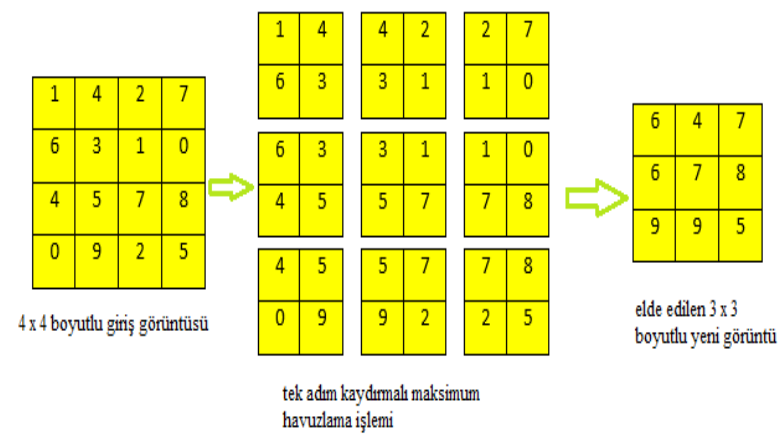

Şekil 5. Maksimum Havuzlama İşlemi Örneği (Figure 5. Example of Maximum Pooling Operation)

Evrişim işlemlerinden sonra elde edilen özellikler tam bağlı yapay sinir ağına girdi verisi olarak verilerek sınıflandırma işlemi gerçekleştirilmiştir. Sınıflandırma aşamasında, ağın ezberlemesini engellemek amaciyla seyreltme değeri kullanılmıştır. Seyreltme, tam bağlı katmanlarda, her tekrarda rastgele bazı düğümlerin iptal edilmesi işlemidir.

Evrişim işlemleri sonucunda elde edilen özellikler, bir katmandaki bütün nöronların bir sonraki katmanın bütün nöronlarına bağlı olduğu tam bağlı katmana girdi olarak verilmektedir. Tam bağlı katmanlarda geleneksel ileri beslemeli sinir ağlarındaki işlemler yapılmaktadır. Tam bağlı katmanlardan elde edilen sonuçlar bir aktivasyon fonksiyonundan geçirilerek sınıflandırma için bir olasılık dağılım haritası tahmin edilmektedir. Aktivasyon fonksiyonu, bir nörona giren verinin çıkış değerinin olup olmayacağını belirleyen bir fonksiyondur. Aktivasyon fonksiyonları, yapay sinir ağlarında doğrusal olmayan gerçek dünya işlemlerini yapmak amacıyla kullanılmaktadır (Kızrak, 2019). Bu çalışmada kullanılan aktivasyon fonksiyonları Şekil 6 ile gösterilmiştir.

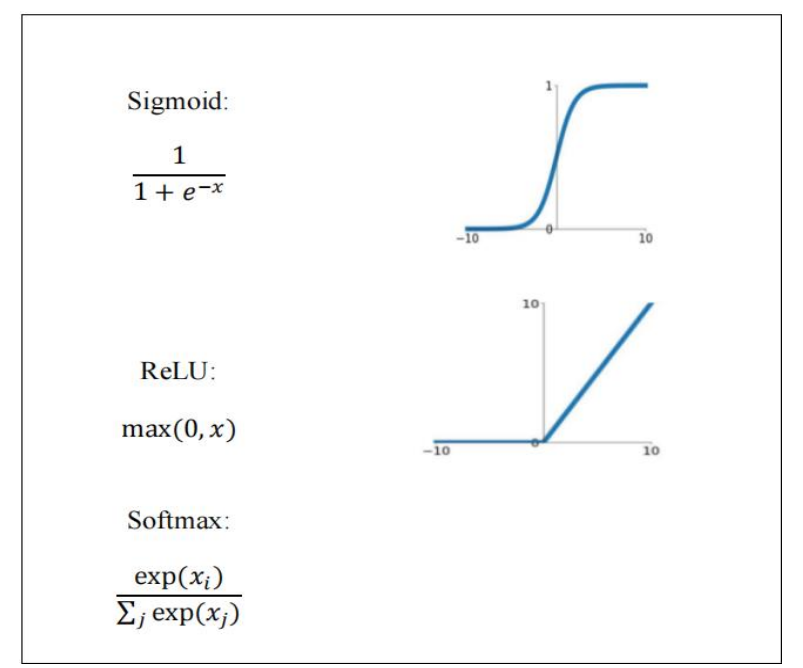

Şekil 6. Mimaride Kullanılan Aktivasyon Fonksiyonları (Figure 6. Activation Functions Used in Architecture)

Bu çalışmada, Sgd, RMSProp, Adam, Adagrad ve Adamax optimizasyon yöntemleri kullanılmıştır. Sgd yönteminin anlaşılabilmesi için türev, gradyan ve gradyan iniş (en dik iniş) kavramlarının bilinmesi gerekmektedir. Türev, bağımsız bir değişkende meydana gelen değişimin bu değişkene bağlı bir fonksiyonda meydana getireceği artışın veya azalışın, bağımsız değişkendeki değişime oranıdır. (1) denkleminde gösterildiği gibi, birden fazla bağımsız değişkene bağlı bir F fonksiyonun her değişken için alınan kısmi türevlerinin vektörü gradyan olarak adlandırılmaktadır.

$$
\nabla F\left(\mathrm{x}_{1}, \mathrm{x}_{2}, \ldots, \mathrm{x}_{\mathrm{n}}\right)=\left(\frac{\partial F}{\partial \mathrm{x}_{1}}, \frac{\partial F}{\partial \mathrm{x}_{2}}, \ldots, \frac{\partial F}{\partial \mathrm{x}_{\mathrm{n}}}\right)
$$

Geri yayılımlı yapay sinir ağlarında öğrenme işlemi, ağa verilen girişlere karşılık gelen çıkışların belli bir hata fonksiyonuna girilmesi ve elde edilen hataların geriye yayılarak ağırlıkların güncellenmesidir. Hata fonksiyonunun hesaplanarak hataların minimuma indirilmesini sağlamak amacıyla gradyan iniş yöntemi kullanılmaktadır.

Gradyan iniş, bir fonksiyon üzerinde rastgele seçilen bir A noktasından başlanarak bu noktanın koordinatlarını kısmi türevlerinin tersi yönünde değiştirilerek fonksiyonun minimum değerine yaklaştırılması yöntemidir (Atasoy, 2011). denkleminde gösterilen $\mathrm{F}$ değeri, gradyan inişi; $\eta$ (eta) değeri, adım kat sayısını ifade etmektedir. Burada önemli bir husus, $\eta$ (eta) değerinin seçimidir. $\eta$ değerinin çok küçük seçilmesi, minimum noktaya ulaşma süresinin uzamasına ve çok büyük seçilmesi de minimum noktanın aşılmasına neden olmaktadır.

$$
F=F(A)-\eta *(\nabla F(A))
$$

Gradyan iniş yönteminde, her güncelleme aşamasında veri setinin tümü için hata fonksiyonu hesaplanmaktadır ve bu işlem çok zaman almaktadır. Gradyan iniş yönteminin bu problemi, (3) denklemi ile gösterildiği gibi her güncelleme aşamasında veri setinin sadece bir örneği için hata fonksiyonu hesaplanan Sgd yöntemi ile çözülmüştür (Anonim, 2019).

$$
F=F\left(A_{i}\right)-\eta *\left(\nabla F\left(A_{i}\right)\right)
$$

RMSProp, Geoffrey Hinton tarafindan önerilen bir optimizasyon yöntemidir. RMSProp yönteminde, ağdaki her ağırlık için öğrenme oranı, o ağırlığın son gradyanlarının aynı ağırlığın büyüklüklerinin ortalama koşma hızına bölünerek elde edilmektedir ve RMSProp yöntemi ile (4) denkleminde gösterildiği gibi w, ağırlık; $t$, zaman ve $\mathrm{E}$, hata değeri olmak üzere her ağırlık için karesel gradyanın hareketli bir ortalaması tutulmaktadır (Hinton vd, 2012).

$$
\operatorname{OrtKare}(w, t)=0.9 *(\operatorname{OrtKare}(w, t-1))+0.1 *\left(\frac{\partial E}{\partial w^{t}}\right)^{2}
$$

Adagrad, her bir parametrenin gradyanlarını yeniden boyutlandıran ve her parametre için bağımsız bir öğrenme hızı sunan özel bir gradyan iniş yöntemidir. Adagrad yönteminde, öğrenme hızı parametrelere göre uyarlanmaktadır; seyrek parametreler için daha büyük güncellemeler ve sik parametreler için daha küçük güncellemeler yapıldığından dolayı seyrek verilerle daha iyi çalışmaktadır (Ruder, 2017).

Adam, Kingma ve Ba tarafindan ortaya atılan birinci derece stokastik gradyan tabanlı ve düşük bellek ihtiyacı olan bir optimizasyon yöntemidir. Adam, büyük veri setleri, büyük parametre değerleri ve çok gürültülü veya seyrek gradyanlı problemler için uygun bir yöntemdir. Adam yöntemi, seyrek gradyanlarla iyi çalışan Adagrad yöntemi ile çevrimiçi ve durağan olmayan ortamlarda iyi çalışan RMSProp yönteminin avantajlarını birleştirmek amacıyla tasarlanmıştır. AdaMax yöntemi de Kingma ve Ba tarafından ortaya atılan sonsuzluk normuna dayanan bir Adam yöntemidir (Kingma ve Ba, 2015).

Sonraki adımda, tahmin ile gerçek değer arasındaki fark olan 
hata (kayıp) fonksiyonu istenen yakınsama oluncaya kadar ağırlıklar güncellenerek tekrar tekrar hesaplanmaktadır. $\mathrm{Bu}$ amaçla, X: tahmini değer ve Y: gerçek değer olmak üzere bu çalışmada kullanılan hata fonksiyonları; (5) denkleminde gösterilen ortalama karesel hata (MSE - Mean Square Error),

$$
M S E=\frac{1}{n}\left[\sum_{i=1}^{n}\left(X_{i}-Y_{i}\right)^{2}\right]
$$

(6) denkleminde gösterilen ortalama mutlak hata (MAE - Mean Absolute Error),

$$
M A E=\frac{1}{n}\left[\sum_{i=1}^{n}\left|X_{i}-Y_{i}\right|\right]
$$

Tablo 1 ile verilen karmaşıklık matrisi ile elde edilen ve (7) denkleminde gösterilen doğruluk değeri,

Tablo 1. Karmaşıklık Matrisi (Table 1. Complexity Matrix)

\begin{tabular}{l|l|l|l}
\hline \multirow{2}{*}{$\begin{array}{l}\text { Karmaşıklık } \\
\text { Matrisi }\end{array}$} & \multicolumn{2}{|l}{ Tahmin Edilen Sınıf } \\
\cline { 3 - 4 } & \multicolumn{1}{l|}{$\begin{array}{l}C+ \\
\text { Gerçek Sınıf }\end{array}$} & $\begin{array}{l}\text { Gerçek } \\
\text { Pozitif (GP) }\end{array}$ & $\begin{array}{l}\text { Yanlış Negatif } \\
(\text { YN) }\end{array}$ \\
\cline { 2 - 4 } & \multirow{2}{*}{$\begin{array}{l}\text { Yanlış Pozitif } \\
(Y P)\end{array}$} & $\begin{array}{l}\text { Gerçek } \\
\text { Negatif (GN) }\end{array}$ \\
\hline
\end{tabular}

$$
D o g ̆ r u l u k=\frac{G P+G N}{G P+G N+Y P+Y N}
$$

Tablo 1 ile verilen karmaşıklık matrisi ile elde edilen ve (8) denkleminde gösterilen hassasiyet değeri,

$$
\text { Hassasiyet }=\frac{G P}{G P+Y P}
$$

Tablo 1 ile verilen karmaşıklık matrisi ile elde edilen ve (9) denkleminde gösterilen hatırlama değeri ve

$$
\text { Hatırlama }=\frac{G P}{G P+Y P}
$$

(8) ve (9) denklemleri kullanılarak elde edilen ve (10) denkleminde gösterilen F1 skorudur.

$$
F_{1}=2 * \frac{\text { Hassasiyet } * \text { Hatırlama }}{\text { Hassasiyet }+ \text { Hatırlama }}
$$

\subsection{Kullanılan Donanım ve Yazılım Araçları}

$\mathrm{Bu}$ çalışmada donanım aracı olarak Google Colab platformunda, NVIDIA'nın 2014 yılında sunduğu ve GPU (Grafik İşleme Birimi) işlemcisine sahip Tesla K80 işlemcili makine kullanılmıştır. Google Colab platformuna bir Google hesabı ile girilebilmektedir. Colab platformunun 12 saate kadar açık tutulabilen bir oturum süresi vardır ve 12 saat sonunda yeni bir oturum açılarak kullanılabilmektedir. NVIDIA Tesla-K80 GPU hızlandırıcı kullanılarak yapılan çalışma için yaklaşık 12 GB (Giga Byte) rastgele erişilebilir bellek (Random Access Memory - RAM) kullanılmıștır. Tesla-K80 işlemcisi çift çekirdekli ve çekirdek hızı $560 \mathrm{MHz}$ (Mega Hertz)' dir. Bu, saniyede 560 milyon işlem yapabilmesi demektir. GPU işlemci kullanan sistemler, CPU (Merkezi İşlem Birimi) işlemci kullanan sistemlere göre daha hızlı performans sağlamakta ve daha düşük düzeyde enerji harcamaktadır (Ortakaya, 2014). Çalışmanın yazılım aşamasında olarak Python programlama dili, Keras ve Numpy kütüphaneleri ve bu kütüphanelerin araçları kullanılmıştır.

\subsubsection{Keras}

Keras, derin öğrenme çalışmaları yapmak amacıyla sunulan, yapay zeka ve makine öğrenmesi yöntemlerini içeren açık kaynak kodlu bir Python kütüphanesidir. Yüksek performanslı işlemler yapabilen ve derin öğrenme çalışmaları için kullanılan Theano ve TensorFlow kütüphaneleri üzerinden çalışmaktadır. GPU ya da CPU üzerinde çalışmasını bu temel kütüphaneler üzerinden sağlamaktadır. Theano, çok boyutlu vektörler olan tensörler üzerinde matematiksel işlemleri hızlıca yapmaya yarayan bir matematik programlama kütüphanesidir. TensorFlow da Theano kütüphanesine benzer olarak hesaplama yapmak amacıyla veri akış grafiklerinin kullanıldığı açık kaynak kodlu bir derin öğrenme kütüphanesidir. İlk kez 2015 yılında ortaya atılan TensorFlow, bir Google ürünüdür ve Theano kütüphanesinden farklı olarak işlemleri birden fazla makineye dağıtabilmektedir (Pişkin, 2017).

Keras kütüphanesi, Theano ve Tensorflow kütüphanelerine göre daha üst düzey bir kütüphane olduğundan dolayı modelleri tanımlamayı ve eğitmeyi çok kolay hale getirmektedir. Böylece, uygulamaların daha kolay geliştirilmesi sağlanmaktadır.

\subsubsection{NumPy Library}

NumPy kütüphanesi, Python'da bilimsel hesaplamalar yapmak amacıyla kullanılan temel pakettir. Çok boyutlu bir dizi nesnesi, çeşitli türetilmiş nesneler (maskelenmiş diziler ve matrisler gibi) ve dizilerdeki hızlı işlemler için matematiksel, mantıksal, şekil işleme, sıralama, seçme, giriş ve çıkış içeren bir dizi yordam sunan bir Python kitaplığıdır.

\section{Araştırma Sonuçları ve Tartıșma}

\subsection{CNN Ağının Eğitilmesi ve Test İşlemleri}

Bu çalışmada, 40000 adet eğitim verisi ve 20000 adet test verisinden oluşan meme patoloji veri setini kanserli ve kanserli olmayan olarak iki sınıfa ayırmak amacıyla 3 evrişim katmanı, 3 ReLU katmanı, 3 havuzlama katmanı ve bir tam bağlı katmana sahip bir mimari kullanılmıştır. Aktivasyon fonksiyonları olarak, gizli katmanlarda ReLU ve tam bağlı katmanda sigmoid fonksiyonları kullanılmıştır. Geliştirilen CNN mimarisinin eğitilmesi aşamasında; optimizasyon algoritmaları, eğitim tur sayısı, seyreltme değeri, katman sayısı ve aktivasyon fonksiyonları gibi çeşitli hiper-parametreler kullanılmıştır. $\mathrm{Bu}$ hiper-parametreler, en başarılı sonuçlar veren mimari elde edilene kadar değiştirilerek denenmiş ve elde edilen sonuçlar ölçülmüştür. Mimarinin başarısını ölçmek amacıyla doğruluk, MSE, MAE, F1 skoru, hatırlama ve hassasiyet metrikleri kullanılmıştır. Filtre boyutu 3x3, filtre sayıs1 32, kaydırma adımı hiper-parametresi 1, aynı anda işlenen görüntü sayısı (batch size) 100, optimizasyon algoritması RMSProp, seyreltme değeri 0.5 , eğitim tur sayısı 25 ve evrişim katman sayısı 3 değerleri kullanılarak tasarlanan mimarinin başarısını ölçmek amacıyla kullanılan ve 1 değerine yakınsaması istenen doğruluk değeri 0.8775 , F1 skoru 0.8238 , hassasiyet değeri 0.8381 ve hatırlama değeri $0.8762 ; 0$ değerine 
yakınsaması istenen MSE değeri 0.1195 ve MAE değeri 0.2497 elde edilmiştir.

Bu çalışmada evrişim işlemleri için farklı boyutlarda filtreler kullanılmıştır. Tablo 2 ve Tablo 3 ile gösterildiği gibi bu filtrelerin eğitim ve test setindeki doğruluk, MSE, MAE, F1, hassasiyet ve hatırlama değerleri ölçülmüsstür. Çizelgeler ile belirtilen eğitim ve test işlemleri için geçen süreler saniye cinsinden hesaplanmıştır.

Tablo 2. Filtre Boyutunun Veri Setindeki Doğruluk, MSE ve MAE Değerleri (Table 2. Accuracy, MSE and MAE Values of the Filter Size in the Data Set)

\begin{tabular}{|c|c|c|c|c|c|c|c|c|}
\hline \multirow{2}{*}{$\begin{array}{l}\text { Filtre } \\
\text { Boyutu }\end{array}$} & \multicolumn{4}{|c|}{ Doğruluk } & \multicolumn{2}{|l|}{ MSE } & \multicolumn{2}{|l|}{ MAE } \\
\hline & $\begin{array}{l}\text { Eğiti } \\
\text { m }\end{array}$ & $\begin{array}{l}\text { Ĕgitim } \\
\text { Süresi }\end{array}$ & Test & $\begin{array}{l}\text { Test } \\
\text { Süresi }\end{array}$ & Eğitim & Test & Eğitim & Test \\
\hline $2 \times 2$ & 0.8200 & 464 & 0.6450 & 232 & 0.1536 & 0.1735 & 0.3243 & 0.3737 \\
\hline $3 \times 3$ & 0.8775 & 466 & 0.8350 & 233 & 0.1195 & 0.1293 & 0.2497 & 0.3064 \\
\hline $4 \times 4$ & 0.7875 & 462 & 0.5850 & 231 & 0.1587 & 0.1840 & 0.3356 & 0.3580 \\
\hline $5 \times 5$ & 0.8550 & 468 & 0.7600 & 234 & 0.1343 & 0.2069 & 0.3224 & 0.3928 \\
\hline $6 x 6$ & 0.8150 & 636 & 0.7700 & 318 & 0.1480 & 0.1717 & 0.2959 & 0.3124 \\
\hline $7 \times 7$ & 0.7950 & 460 & 0.5350 & 230 & 0.1612 & 0.2584 & 0.3407 & 0.3754 \\
\hline
\end{tabular}

Tablo 3. Filtre Boyutunun Veri Setindeki F1, Hassasiyet ve Hatırlama Değerleri (Table 3. F1, Sensitivity and Recall Values of the Filter Size in the Data Set)

\begin{tabular}{l|l|l|l|l|l|l}
\hline \multirow{2}{*}{ Filtre Boyutu } & \multicolumn{2}{|l|}{ F1 Skoru } & \multicolumn{2}{l|}{ Hassasiyet } & \multicolumn{2}{l}{ Haturlama } \\
\cline { 2 - 7 } & Ĕgitim & Test & Eğitim & Test & Ĕgitim & Test \\
\hline \hline $2 x 2$ & 0.7981 & 0.7121 & 0.8036 & 0.7357 & 0.7968 & 0.7671 \\
\hline $3 \times 3$ & 0.8238 & 0.8172 & 0.8381 & 0.8357 & 0.8762 & 0.8528 \\
\hline $4 \times 4$ & 0.7565 & 0.5342 & 0.8060 & 0.6525 & 0.7558 & 0.7218 \\
\hline $5 \times 5$ & 0.8013 & 0.7862 & 0.8292 & 0.6434 & 0.8130 & 0.6956 \\
\hline $6 x 6$ & 0.7572 & 0.6219 & 0.7938 & 0.5573 & 0.8059 & 0.7757 \\
\hline $7 x 7$ & 0.7521 & 0.5758 & 0.7635 & 0.6628 & 0.8027 & 0.7097 \\
\hline
\end{tabular}

$\mathrm{Bu}$ çalışmada geliştirilen mimari için $3 \times 3$ boyutlu filtreler kullanılmıştır. Bu filtrelerin kullanılmasıyla Şekil 7 ile gösterilen (a) doğruluk ve (b) MSE grafiklerinde görüldüğü gibi yüksek doğruluk ve düşük MSE değerleri elde edilmiştir. Filtre boyutu $8 \times 8$ ve daha büyük filtreler için bu mimarinin eğitilemediği gözlemlenmiştir.

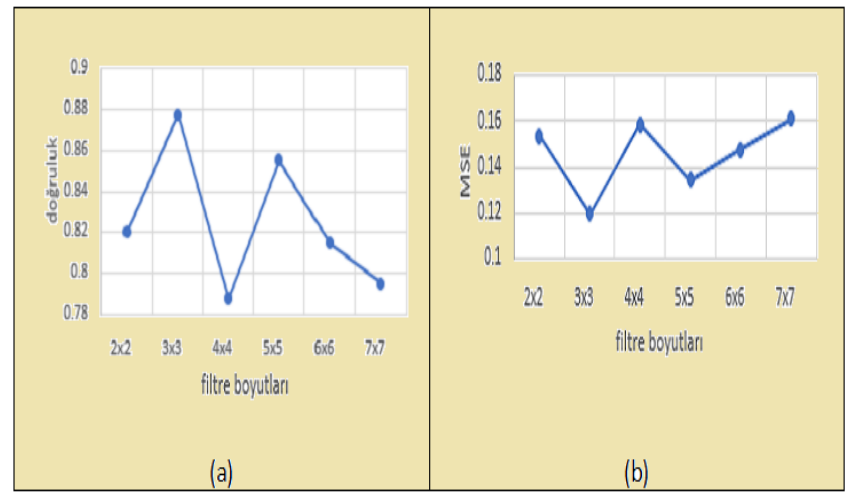

Şekil 7. Filtre Boyutlarına Göre (a) Doğruluk ve (b) MSE Grafikleri (Figure 7. (a) Accuracy and (b) MSE Plots by Filter Dimensions)

Filtrelerin sayılarının değiştirilmesiyle elde edilen doğruluk, MSE, MAE, F1, hassasiyet ve hatırlama değerleri Tablo 4 ve Tablo 5 ile gösterilmiştir.

Tablo 4. Filtre Sayısının Ĕ̈itim ve Test Setlerindeki Doğruluk, MSE ve MAE Değerleri (Table 4. Accuracy, MSE and MAE Values of the Number of Filters in Training and Test Sets)

\begin{tabular}{l|l|l|l|l|l|l|l|l}
\hline \multirow{2}{*}{$\begin{array}{l}\text { Filtre } \\
\text { Sayısı }\end{array}$} & \multicolumn{4}{|c|}{ Doğruluk } & \multicolumn{2}{l}{ MSE } & \multicolumn{2}{l}{ MAE } \\
\cline { 2 - 9 } & Eğitim & $\begin{array}{l}\text { Eğitim } \\
\text { Süresi }\end{array}$ & Test & $\begin{array}{l}\text { Test } \\
\text { Süresi }\end{array}$ & Eğitim & Test & Eğitim & Test \\
\hline \hline 10 & 0.7350 & 476 & 0.7050 & 238 & 0.1646 & 0.1863 & 0.3822 & 0.4032 \\
\hline 20 & 0.8525 & 472 & 0.7950 & 236 & 0.1331 & 0.1407 & 0.3331 & 0.3596 \\
\hline 32 & 0.8775 & 466 & 0.8350 & 233 & 0.1195 & 0.1293 & 0.2497 & 0.3064 \\
\hline 60 & 0.8150 & 396 & 0.7450 & 198 & 0.1505 & 0.1990 & 0.3334 & 0.3816 \\
\hline 70 & 0.8025 & 408 & 0.6000 & 204 & 0.1668 & 0.1813 & 0.3364 & 0.4531 \\
\hline
\end{tabular}

Tablo 5. Filtre Sayısının Veri Setindeki F1, Hassasiyet ve Hatırlama Değerleri(Table 5. F1, Sensitivity and Recall Values of the Number of Filters in the Data Set)

\begin{tabular}{l|l|l|l|l|l|l}
\hline \multirow{2}{*}{$\begin{array}{l}\text { Filtre } \\
\text { Sayısı }\end{array}$} & \multicolumn{2}{|l|}{ F1 Skoru } & \multicolumn{2}{l|}{ Hassasiyet } & \multicolumn{2}{l}{ Hatırlama } \\
\cline { 2 - 7 } & Eğitim & Test & Eğitim & Test & Eğitim & Test \\
\hline \hline 10 & 0.7462 & 0.7017 & 0.7857 & 0.7429 & 0.7979 & 0.7829 \\
\hline 20 & 0.8186 & 0.7894 & 0.8228 & 0.7558 & 0.8428 & 0.8125 \\
\hline 32 & 0.8238 & 0.8172 & 0.8381 & 0.8357 & 0.8762 & 0.8528 \\
\hline 60 & 0.7886 & 0.6151 & 0.8189 & 0.6846 & 0.8229 & 0.8116 \\
\hline 70 & 0.7797 & 0.7662 & 0.7971 & 0.7110 & 0.8062 & 0.7964 \\
\hline
\end{tabular}

$\mathrm{Bu}$ çalışma için seçilen filtre sayısı 32' dir. 32 değerinden daha fazla filtre sayıları kullanıldığında Şekil 8 (a) doğruluk grafiğinde gösterildiği gibi mimarinin başarısının artmadığı ve (b) MSE grafiğinde gösterildiği gibi hata değerinin arttığ görülmektedir. 


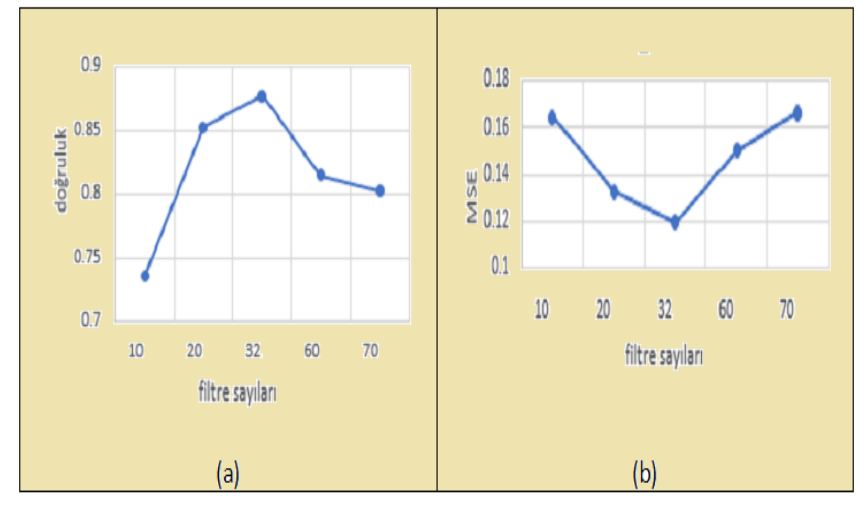

Şekil 8. Filtre Sayılarına Göre (a) Doğruluk ve (b) MSE Grafikleri (Figure 8. (a) Accuracy and (b) MSE Graphs by Filter Numbers)

Kaydırma adımı, görüntü üzerinde filtreleme yapılırken atlanan piksel sayısını ifade etmektedir. Kaydırma adımlarının değiştirilmesiyle eğitim ve test setlerindeki doğruluk, MSE, MAE, F1, hassasiyet ve hatırlama değerleri Tablo 6 ve Tablo 7 ile verilmiştir.

Tablo 6. Kaydırma Adımlarının Veri Setindeki Doğruluk, MSE ve MAE Değerleri (Table 6. Accuracy, MSE and MAE Values of Shift Steps in Data Set)

\begin{tabular}{l|l|l|l|l|l|l|l|l}
\hline \multirow{2}{*}{$\begin{array}{l}\text { Kaydırma } \\
\text { Adımları }\end{array}$} & \multicolumn{4}{|c|}{ Doğruluk } & \multicolumn{2}{c|}{ MSE } & \multicolumn{2}{l}{ MAE } \\
\cline { 2 - 9 } & Eğitim & $\begin{array}{l}\text { Ĕgitim } \\
\text { Süresi }\end{array}$ & Test & $\begin{array}{l}\text { Test } \\
\text { Süresi }\end{array}$ & Eğitim & Test & Ĕgitim & Test \\
\hline \hline 1 & 0.8775 & 466 & 0.8350 & 233 & 0.1195 & 0.1293 & 0.2497 & 0.3064 \\
\hline 2 & 0.8125 & 408 & 0.7450 & 204 & 0.1323 & 0.1488 & 0.2989 & 0.3518 \\
\hline 3 & 0.7500 & 384 & 0.6300 & 192 & 0.1439 & 0.1524 & 0.3395 & 0.3666 \\
\hline 4 & 0.7625 & 380 & 0.6300 & 190 & 0.1631 & 0.1638 & 0.3832 & 0.4079 \\
5 & 0.7825 & 378 & 0.5250 & 189 & 0.1651 & 0.2416 & 0.4374 & 0.4244 \\
\hline
\end{tabular}

Tablo 7. Kaydırma Adımlarının Veri Setindeki F1, Hassasiyet ve Hatırlama Değerleri (Table 7. F1, Sensitivity and Recall Values of Shift Steps in the Data Set)

\begin{tabular}{l|l|l|l|l|l|l}
\hline \multirow{2}{*}{$\begin{array}{l}\text { Kaydırma } \\
\text { Adımı }\end{array}$} & \multicolumn{2}{|l|}{ F1 Skoru } & \multicolumn{2}{l|}{ Hassasiyet } & \multicolumn{2}{l}{ Hatırlama } \\
\cline { 2 - 7 } & Eğitim & Test & Eğitim & Test & Eğitim & Test \\
\hline \hline$I$ & 0.8238 & 0.8172 & 0.8381 & 0.8357 & 0.8762 & 0.8528 \\
\hline 2 & 0.8178 & 0.7458 & 0.8029 & 0.7739 & 0.8331 & 0.8179 \\
\hline 3 & 0.7824 & 0.6964 & 0.7339 & 0.6841 & 0.8107 & 0.8058 \\
\hline 4 & 0.7828 & 0.6353 & 0.7764 & 0.6999 & 0.8165 & 0.7912 \\
\hline 5 & 0.7721 & 0.6327 & 0.7670 & 0.6360 & 0.8390 & 0.6900 \\
\hline
\end{tabular}

Bu çalışmada, kaydırma adımı 1 olarak seçilmiştir. Bu değer, Şekil 9 ile verilen (a) doğruluk ve (b) MSE grafiklerinde görüldüğü gibi mimari için en iyi sonuçları vermiştir. Kaydırma adımı arttırıldığında mimarinin başarısının artmadığı ve hata oranının arttığı görülmüştür.

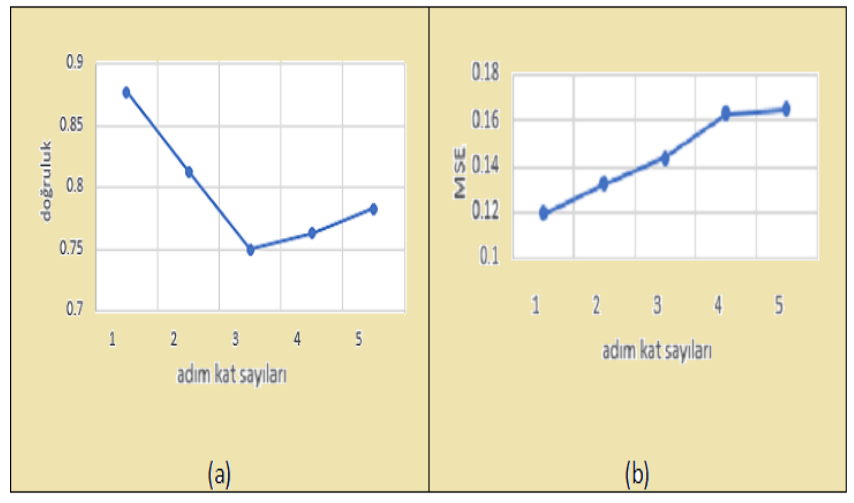

Şekil 9. Kaydırma Adımlarına Göre (a) Doğruluk ve (b) MSE Grafikleri (Figure 9. (a) Accuracy and (b) MSE Plots by Shift Steps)

Evrişim katman sayılarının değiştirilmesiyle eğitim ve test setlerindeki doğruluk, MSE, MAE, F1, hassasiyet ve hatırlama değerleri Tablo 8 ve Tablo 9 ile verilmiştir. 1, 2, 3 ve 4 evrişim katman sayıları ile mimari eğitilirken aynı sayıda havuzlama katmanları kullanılmıştır. 5, 6 ve 7 evrişim katman sayıları için aynı sayıda havuzlama katmanı kullanıldığında görüntü boyutları eğitim sırasında işlenemeyecek kadar küçülmüştür. Bu nedenle 5, 6 ve 7 evrişim katmanları için ikişer havuzlama katmanı kullanılmıştır.

Tablo 8. Evrişim Katman Sayısının Veri Setindeki Doğruluk, MSE ve MAE Değerleri (Table 8. Accuracy, MSE and MAE Values of Convolutional Layer Number in the Data Set)

\begin{tabular}{l|l|l|l|l|l|l|l|l}
\hline \multirow{2}{*}{$\begin{array}{l}\text { Evrişim } \\
\text { Katman } \\
\text { Sayısı }\end{array}$} & \multicolumn{4}{|c|}{ Doğruluk } & \multicolumn{2}{l|}{ MSE } & \multicolumn{2}{l}{ MAE } \\
\cline { 2 - 9 } & Eğitim & $\begin{array}{l}\text { Ĕgitim } \\
\text { Süresi }\end{array}$ & Test & $\begin{array}{l}\text { Test } \\
\text { Süresi }\end{array}$ & Eğitim & Test & Ĕgitim & Test \\
\hline \hline 1 & 0.8275 & 502 & 0.8050 & 251 & 0.1560 & 0.1655 & 0.2990 & 0.3352 \\
\hline 2 & 0.8075 & 530 & 0.7100 & 265 & 0.1569 & 0.1773 & 0.3256 & 0.3537 \\
\hline 3 & 0.8775 & 466 & 0.8350 & 233 & 0.1195 & 0.1293 & 0.2497 & 0.3064 \\
\hline 4 & 0.8350 & 468 & 0.7750 & 234 & 0.1369 & 0.1608 & 0.3329 & 0.3958 \\
\hline 5 & 0.8275 & 440 & 0.7750 & 220 & 0.1567 & 0.1720 & 0.3566 & 0.4105 \\
\hline 7 & 0.8050 & 436 & 0.8000 & 218 & 0.1611 & 0.1644 & 0.3482 & 0.3490 \\
\hline
\end{tabular}

Tablo 9. Evrişim Katman Sayısının Veri Setindeki F1, Hassasiyet ve Hatırlama Değerleri (Table 9. F1, Sensitivity and Recall Values of Convolutional Layer Number in the Data Set)

\begin{tabular}{l|l|l|l|l|l|l}
\hline \multirow{2}{*}{$\begin{array}{l}\text { Evrişim } \\
\text { Katman } \\
\text { Sayısı }\end{array}$} & \multicolumn{2}{|l|}{ F1 Skoru } & \multicolumn{2}{l|}{ Hassasiyet } & \multicolumn{2}{l}{ Hatırlama } \\
\cline { 2 - 7 } & Eğitim & Test & Eğitim & Test & Eğitim & Test \\
\hline \hline$I$ & 0.8041 & 0.7963 & 0.8244 & 0.7605 & 0.8320 & 0.7785 \\
\hline 2 & 0.8182 & 0.8058 & 0.8010 & 0.7916 & 0.8423 & 0.8137 \\
\hline 3 & 0.8238 & 0.8172 & 0.8381 & 0.8357 & 0.8762 & 0.8528 \\
\hline 4 & 0.8214 & 0.6684 & 0.8275 & 0.8160 & 0.8430 & 0.8381 \\
\hline 5 & 0.8210 & 0.7938 & 0.8019 & 0.7733 & 0.8393 & 0.7803 \\
\hline 7 & 0.8021 & 0.8017 & 0.8141 & 0.7921 & 0.8151 & 0.7745 \\
\hline
\end{tabular}


Bu çalışma için evrişim katman sayısı 3 olarak seçilmiştir. 3 değeri için Şekil 10 ile gösterilen (a) doğruluk değeri en büyük ve (b) MSE değeri en küçük olarak ölçülmüştür. Evrişim katman sayısının arttırılmasıyla mimarinin daha iyi sonuçlara ulaşamadığ görülmüştür.

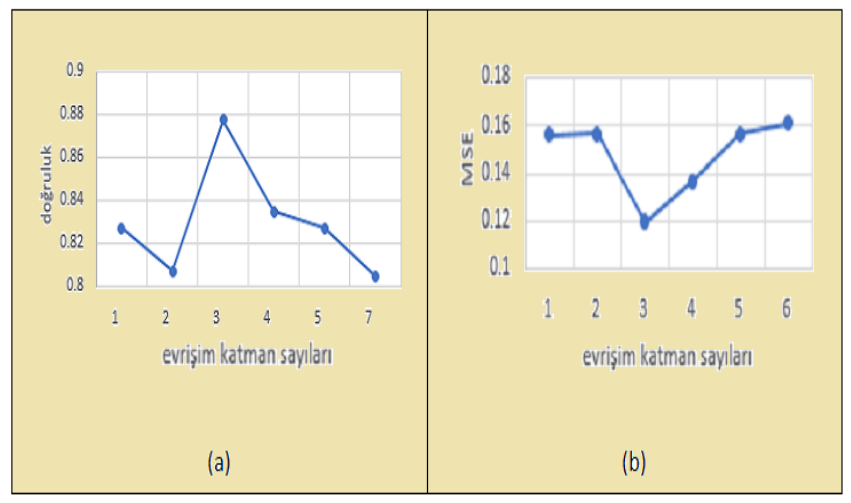

Şekil 10. Evrişim Katman Sayılarına Göre (a) Doğruluk ve (b) MSE Grafikleri (Figure 10. (a) Accuracy and (b) MSE Plots by Convolutional Layer Numbers)

$\mathrm{Bu}$ çalışmada kullanılan hiper-parametrelerden biri de optimizasyon algoritmalarıdır. Optimizasyon algoritmalarının mimarinin eğitim ve test setlerindeki doğruluk, MSE, MAE, F1, hassasiyet ve hatırlama değerleri Tablo 10 ve Tablo 11 ile gösterilmiştir.

Tablo 10. Optimizasyon Algoritmalarının Veri Setindeki Doğruluk, MSE ve MAE Değerleri (Table 10. Accuracy, MSE and MAE Values of Optimization Algorithms in the Data Set)

\begin{tabular}{l|l|l|l|l|ll|l|l}
\hline \multirow{2}{*}{$\begin{array}{l}\text { Optimizasyo } \\
\text { n } \\
\text { Algoritmalar } \\
\mathbf{I}\end{array}$} & \multicolumn{4}{|c|}{ Doğruluk } & \multicolumn{2}{|l}{ MSE } & \multicolumn{2}{c}{ MAE } \\
\cline { 2 - 9 } & $\begin{array}{l}\text { Eğiti } \\
\mathbf{m}\end{array}$ & $\begin{array}{l}\text { Eğiti } \\
\mathbf{m} \\
\text { Süresi }\end{array}$ & Test & $\begin{array}{l}\text { Test } \\
\text { Süres } \\
\mathbf{i}\end{array}$ & $\begin{array}{l}\text { Eğiti } \\
\mathbf{m}\end{array}$ & Test & $\begin{array}{l}\text { Eğiti } \\
\mathbf{m}\end{array}$ & Test \\
\hline \hline Sgd & 0.6175 & 414 & $\begin{array}{l}0.510 \\
0\end{array}$ & 212 & 0.2380 & $\begin{array}{l}0.238 \\
8\end{array}$ & 0.4892 & $\begin{array}{l}0.490 \\
5\end{array}$ \\
\hline Adagrad & 0.8200 & 400 & $\begin{array}{l}0.815 \\
0\end{array}$ & 200 & 0.1519 & $\begin{array}{l}0.156 \\
4\end{array}$ & 0.2886 & $\begin{array}{l}0.295 \\
0\end{array}$ \\
\hline Adamax & 0.8175 & 438 & $\begin{array}{l}0.795 \\
0\end{array}$ & 219 & 0.1356 & $\begin{array}{l}0.175 \\
8\end{array}$ & 0.2918 & $\begin{array}{l}0.300 \\
7\end{array}$ \\
\hline Adam & 0.8025 & 486 & $\begin{array}{l}0.780 \\
0\end{array}$ & 243 & 0.1302 & $\begin{array}{l}0.135 \\
6\end{array}$ & 0.2739 & $\begin{array}{l}0.315 \\
5\end{array}$ \\
\hline RMSProp & 0.8775 & 466 & $\begin{array}{l}0.835 \\
0\end{array}$ & 233 & 0.1195 & $\begin{array}{l}0.129 \\
3\end{array}$ & 0.2497 & $\begin{array}{l}0.306 \\
4\end{array}$ \\
\hline
\end{tabular}

Tablo 11. Optimizasyon Algoritmalarının Veri Setindeki F1,

Hassasiyet ve Hatırlama Değerleri (Table 11. F1, Sensitivity and Recall Values of Optimization Algorithms in the Data Set)

\begin{tabular}{l|l|l|l|l|l|l}
\hline \multirow{2}{*}{$\begin{array}{l}\text { Optimizasyon } \\
\text { Algoritmaları }\end{array}$} & \multicolumn{2}{|l|}{ F1 Skoru } & \multicolumn{2}{l|}{ Hassasiyet } & \multicolumn{2}{l}{ Hattrlama } \\
\cline { 2 - 7 } & Eğitim & Test & Eğitim & Test & Eğitim & Test \\
\hline \hline Sgd & 0.6974 & 0.6264 & 0.5454 & 0.4982 & 0.6168 & - \\
\hline Adagrad & 0.8051 & 0.8013 & 0.8103 & 0.7899 & 0.8467 & 0.7223 \\
\hline Adamax & 0.8176 & 0.8011 & 0.8084 & 0.7532 & 0.8199 & 0.7799 \\
\hline Adam & 0.7961 & 0.7910 & 0.8026 & 0.7962 & 0.8375 & 0.7413 \\
\hline RMSProp & 0.8238 & 0.8172 & 0.8381 & 0.8357 & 0.8762 & 0.8528 \\
\hline
\end{tabular}

$\mathrm{Bu}$ çalışma için seçilen RMSProp algoritmasının en iyi sonucu verdiği ve Sgd algoritmasının en kötü sonucu verdiği Şekil 11 ile verilen (a) doğruluk ve (b) MSE grafikleri ile gösterilmektedir. Ayrıca, Tablo 11 ile gösterildiği gibi Sgd algoritması için test setinde hatırlama değeri ölçülememektedir.

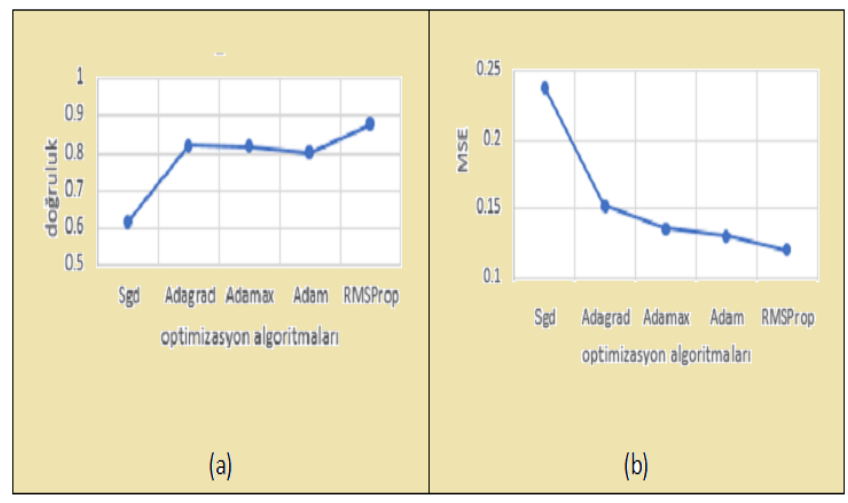

Şekil 11. Optimizasyon Algoritmalarına Göre (a) Doğruluk ve (b) MSE Grafikleri (Figure 11. (a) Accuracy and (b) MSE Plots by Optimization Algorithms)

Eğitim tur sayılarının mimarinin eğitim ve test setlerindeki doğruluk, MSE, MAE, F1, hassasiyet ve hatırlama değerleri Tablo 12 ve Tablo 13 ile verilmiştir. Eğitim tur sayısının belli bir sayının altında veya üstünde seçilmesi mimarinin başarısını düşürmektedir.

Tablo 12. Eğitim Tur Sayısının Veri Setindeki Doğruluk, MSE ve MAE Değerleri (Table 12. Accuracy, MSE and MAE Values in the Data Set of the Number of Training Rounds)

\begin{tabular}{l|c|l|l|l|l|l|l|c}
\hline $\begin{array}{l}\text { Eğitim } \\
\text { Tur } \\
\text { Sayısı }\end{array}$ & \multicolumn{5}{|c|}{ Doğruluk } & \multicolumn{2}{l|}{ MSE } & \multicolumn{2}{l}{ MAE } \\
\cline { 2 - 9 } & Eğitim & $\begin{array}{l}\text { Eğitim } \\
\text { Süresi }\end{array}$ & Test & $\begin{array}{l}\text { Test } \\
\text { Süresi }\end{array}$ & Eğitim & Test & Eğitim & Test \\
\hline \hline 3 & 0.5625 & 356 & 0.4800 & 178 & 0.2349 & 0.2728 & 0.4496 & 0.4651 \\
& & & & & & & & \\
\hline 5 & 0.7300 & 366 & 0.5250 & 183 & 0.2088 & 0.2658 & 0.4209 & 0.4411 \\
\hline 15 & 0.7925 & 396 & 0.7700 & 198 & 0.1600 & 0.1888 & 0.3469 & 0.3860 \\
\hline 25 & 0.8775 & 466 & 0.8350 & 233 & 0.1195 & 0.1293 & 0.2497 & 0.3064 \\
\hline 30 & 0.8200 & 532 & 0.8000 & 266 & 0.1494 & 0.1528 & 0.3054 & 0.3649 \\
\hline 45 & 0.8425 & 540 & 0.8150 & 270 & 0.1296 & 0.1323 & 0.3030 & 0.3198 \\
& & & & & & & & \\
\hline
\end{tabular}

Tablo 13. Eğitim Tur Sayısının Veri Setindeki F1, Hassasiyet ve Hatırlama Değerleri (Table 13. F1, Sensitivity and Recall Values in the Data Set of the Number of Training Rounds)

\begin{tabular}{l|l|l|l|l|l|l}
\hline \multirow{2}{*}{$\begin{array}{l}\text { Eğitim } \\
\text { Tur Sayısı }\end{array}$} & \multicolumn{2}{|l|}{ F1 Skoru } & \multicolumn{2}{l}{ Hassasiyet } & \multicolumn{2}{l}{ Hatırlama } \\
\cline { 2 - 7 } & Eğitim & Test & Eğitim & Test & Eğitim & Test \\
\hline \hline 3 & 0.6687 & 0.6481 & 0.6670 & 0.5800 & 0.6460 & - \\
\hline 5 & 0.7080 & 0.6622 & 0.7286 & 0.5874 & 0.6348 & - \\
\hline 15 & 0.7711 & 0.6904 & 0.7952 & 0.6258 & 0.8136 & 0.7640 \\
\hline 25 & 0.8238 & 0.8172 & 0.8381 & 0.8357 & 0.8762 & 0.8528 \\
\hline 30 & 0.8144 & 0.8095 & 0.8001 & 0.7691 & 0.8281 & 0.7954 \\
\hline 45 & 0.8200 & 0.7601 & 0.8206 & 0.6843 & 0.8378 & 0.8099 \\
\hline
\end{tabular}


$\mathrm{Bu}$ çalışma için seçilen eğitim tur sayısı değeri $25^{\prime}$ tir. 25 değerinin, bu mimari için en başarılı sonucu verdiği, Şekil 12 ile verilen (a) doğruluk ve (b) MSE grafiklerinde görülmektedir. Ayrıca, eğitim tur sayısı arttırıldıkça hem eğitim süresinin arttığ 1 hem de mimarinin başarısının düştüğü görülmüştür. Tablo 13' de gösterildiği gibi 3 ve 5 eğitim tur sayıları için test setinde hatırlama değerleri ölçülememektedir.

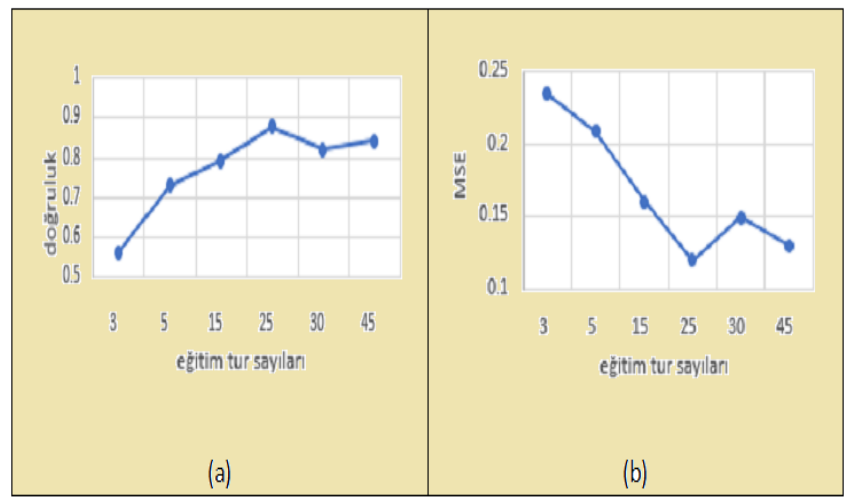

Şekil 12. Eğitim Tur Sayılarına Göre (a) Doğruluk ve (b) MSE Grafikleri (Figure 12. (a) Accuracy and (b) MSE Graphs by Training Round Numbers)

Bu çalışmada kullanılan diğer bir hiper-parametre seyreltme değeridir. Ağın ezberlemesini önlemek amacıyla kullanılan seyreltme değerlerinin eğitim ve test setlerinde kullanılarak elde edilen doğruluk, MSE, MAE, F1, hassasiyet ve hatırlama değerleri Tablo 14 ve Tablo 15 ile gösterilmiştir.

Tablo 14. Seyreltme Değerinin Veri Setindeki Doğruluk, MSE ve MAE Değerleri (Table 14. Accuracy, MSE and MAE Values of the Dropout Value in the Data Set)

\begin{tabular}{l|l|l|l|l|l|l|l|l}
\hline $\begin{array}{l}\text { Seyreltme } \\
\text { Değeri }\end{array}$ & \multicolumn{5}{|c|}{ Doğruluk } & \multicolumn{2}{l|}{ MSE } & \multicolumn{2}{l}{ MAE } \\
\cline { 2 - 9 } & Eğitim & $\begin{array}{l}\text { Eğitim } \\
\text { Süresi }\end{array}$ & Test & $\begin{array}{l}\text { Test } \\
\text { Süresi }\end{array}$ & Eğitim & Test & Eğitim & Test \\
\hline \hline 0.0 & 0.8375 & 660 & 0.7950 & 330 & 0.1340 & 0.2060 & 0.2990 & 0.3147 \\
& & & & & & & & \\
\hline 0.1 & 0.8050 & 644 & 0.7100 & 322 & 0.1617 & 0.2850 & 0.3131 & 0.3721 \\
& & & & & & & & \\
\hline 0.2 & 0.7675 & 632 & 0.6750 & 316 & 0.1867 & 0.2601 & 0.3178 & 0.4050 \\
\hline 0.3 & 0.8025 & 582 & 0.7100 & 291 & 0.1798 & 0.2071 & 0.3107 & 0.3728 \\
\hline 0.4 & 0.8075 & 520 & 0.7400 & 260 & 0.1488 & 0.1861 & 0.3120 & 0.3440 \\
& & & & & & & & \\
\hline 0.5 & 0.8775 & 466 & 0.8350 & 233 & 0.1195 & 0.1293 & 0.2497 & 0.3064 \\
& & & & & & & & \\
\hline
\end{tabular}

Tablo 15. Seyreltme Değerinin Veri Setindeki F1, Hassasiyet ve Hatırlama Değerleri (Table 15. F1, Sensitivity and Recall Values of the Dropout Value in the Data Set)

\begin{tabular}{l|l|l|l|l|l|l}
\hline \multirow{2}{*}{$\begin{array}{l}\text { Seyreltme } \\
\text { Değeri }\end{array}$} & \multicolumn{2}{|l|}{ F1 Skoru } & \multicolumn{2}{l|}{ Hassasiyet } & \multicolumn{2}{l}{ Hatırlama } \\
\cline { 2 - 7 } & Ĕgitim & Test & Ĕgitim & Test & Eğitim & Test \\
\hline \hline 0.0 & 0.8138 & 0.7817 & 0.8347 & 0.8290 & 0.8352 & 0.7500 \\
\hline 0.1 & 0.7744 & 0.7636 & 0.7889 & 0.7542 & 0.8106 & 0.6861 \\
\hline 0.2 & 0.7332 & 0.7327 & 0.7824 & 0.7667 & 0.7682 & 0.7216 \\
\hline 0.3 & 0.7929 & 0.7794 & 0.8027 & 0.7525 & 0.7860 & 0.7763 \\
\hline 0.4 & 0.8049 & 0.7678 & 0.8094 & 0.7678 & 0.8298 & 0.7929 \\
\hline 0.5 & 0.8238 & 0.8172 & 0.8381 & 0.8357 & 0.8762 & 0.8528 \\
\hline
\end{tabular}

Şekil 13 ile gösterilen (a) doğruluk ve (b) MSE grafiklerinde 0.5 seyreltme değerinin mimari için en yüksek doğruluk ve en düşük hata değerlerini verdiği görülmektedir.

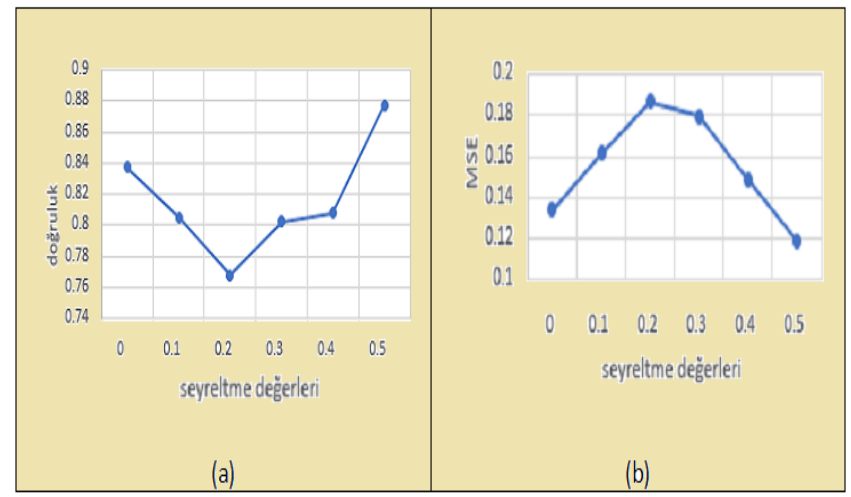

Şekil 13. Seyreltme Değerlerine Göre (a) Doğruluk ve (b) MSE Grafikleri (Figure 13. (a) Accuracy and (b) MSE Plots by Dropout Values)

Bu çalışmada, ağda aynı anda işlenen görüntü sayısı (batch size) arttırıldıkça eğitim için harcanan zaman azalmıştır. Ancak burada dikkat edilmesi gereken husus, ağın başarısının nasıl etkilendiğidir. Bu çalışma için aynı anda işlenen görüntü sayısı 100 olarak seçilmiştir ve aynı anda işlenen görüntü sayılarının mimarinin eğitim ve test setleri için doğruluk, MSE, MAE, F1, hassasiyet ve hatırlama değerleri Tablo 16 ve Tablo 17 ile gösterilmiştir. Ayrıca, aynı anda işlenen görüntü sayısı 1 olarak seçildiğinde ağın 4 saat çalışıp bellek hatası vererek durduğu gözlemlenmiştir. 
Tablo 16. Aynı Anda İşlenen Görüntü Sayısının Veri Setindeki Doğruluk, MSE ve MAE Değerleri (Table 16. Accuracy, MSE and MAE Values of the Number of Images Processed Simultaneously in the Data Set)

\begin{tabular}{|c|c|c|c|c|c|c|c|c|}
\hline \multirow{2}{*}{$\begin{array}{l}\text { Aynı } \\
\text { Anda } \\
\text { İşlenen } \\
\text { Görüntü } \\
\text { Sayısı }\end{array}$} & \multicolumn{4}{|c|}{ Doğruluk } & \multicolumn{2}{|l|}{ MSE } & \multicolumn{2}{|l|}{ MAE } \\
\hline & Eğitim & $\begin{array}{l}\text { Eğitim } \\
\text { Süresi }\end{array}$ & Test & $\begin{array}{l}\text { Test } \\
\text { Süresi }\end{array}$ & Eğitim & Test & Eğitim & Test \\
\hline 10 & 0.8527 & 1014 & 0.8170 & 507 & 0.1299 & 0.1993 & 0.2358 & 0.3499 \\
\hline 50 & 0.8375 & 602 & 0.8025 & 301 & 0.1517 & 0.1562 & 0.2574 & 0.3309 \\
\hline 100 & 0.8775 & 466 & 0.8350 & 233 & 0.1195 & 0.1293 & 0.2497 & 0.3064 \\
\hline 200 & 0.7900 & 442 & 0.7600 & 221 & 0.1881 & 0.2181 & 0.4176 & 0.4313 \\
\hline 500 & 0.7140 & 420 & 0.7060 & 210 & 0.2395 & 0.2484 & 0.4268 & 0.4797 \\
\hline
\end{tabular}

Tablo 17. Aynı Anda İşlenen Görüntü Sayısının Veri Setindeki F1, Hassasiyet ve Hatırlama Değerleri (Table 17. F1, Sensitivity and Recall Values of the Number of Images Processed Simultaneously in the Data Set)

\begin{tabular}{|c|c|c|c|c|c|c|}
\hline \multirow{2}{*}{$\begin{array}{l}\text { Aynı Anda } \\
\text { İşlenen } \\
\text { Görüntü } \\
\text { Sayısı }\end{array}$} & \multicolumn{2}{|c|}{ F1 Skoru } & \multicolumn{2}{|c|}{ Hassasiyet } & \multicolumn{2}{|c|}{ Hatırlama } \\
\hline & Eğitim & Test & Eğitim & Test & Eğitim & Test \\
\hline 10 & 0.8147 & 0.8123 & 0.8310 & 0.8164 & 0.8313 & 0.8311 \\
\hline 50 & 0.8041 & 0.7709 & 0.8226 & 0.7940 & 0.8093 & 0.7936 \\
\hline 100 & 0.8238 & 0.8172 & 0.8381 & 0.8357 & 0.8762 & 0.8528 \\
\hline 200 & 0.7879 & 0.7186 & 0.7917 & 0.7563 & 0.7865 & 0.7526 \\
\hline 500 & 0.7437 & 0.7381 & 0.7727 & 0.7353 & 0.7213 & 0.6582 \\
\hline
\end{tabular}

100 değeri, Şekil 14 ile gösterilen (a) doğruluk grafiği için en yüksek değeri sağlarken (b) MSE grafiği için en düşük değeri, 10 değerinin sağladığı görülmüştür. Ancak 10 değeri için doğruluk değerleri daha düşüktür ve ağın eğitilmesi için gereken süre daha fazladir.

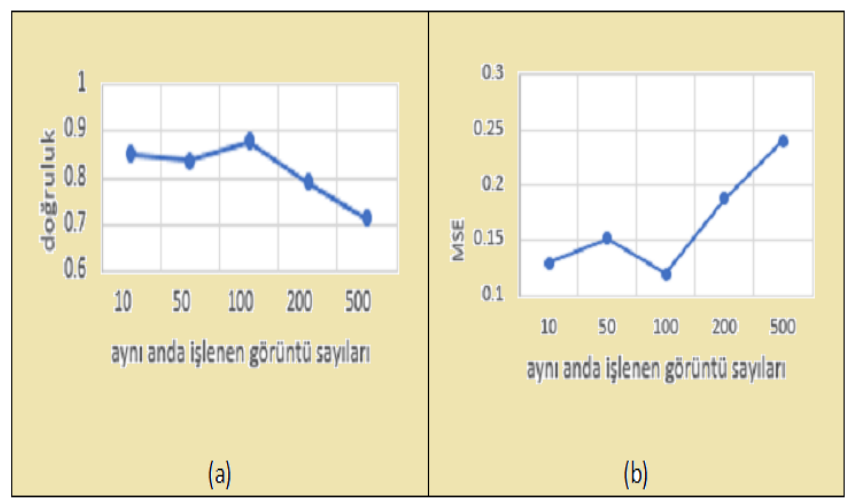

Şekil 14. Aynı Anda İşlenen Görüntü Sayılarına Göre (a) Doğruluk ve (b) MSE Grafikleri (Figure 14. (a) Accuracy and (b) MSE Plots by Number of Images Processed Simultaneously)
$\mathrm{Bu}$ çalışmada CNN ağına verilen görüntülerin boyutları, evrişim ve havuzlama katmanlarında giriş görüntüsünün boyutu, özellik çıkarıcı filtre boyutu ve sayısı, kaydırma adımı, evrişim katman sayısı ve havuzlama katman sayısı parametrelerine göre hesaplanmaktadır. Her havuzlama katmanında bu boyutlar yarıya düşürülmektedir. Evrişim işlemleri sonunda elde edilen görüntü boyutları tek boyutlu vektör haline getirilerek tam bağlı yapay sinir ağına giriş verisi olarak verilmektedir. Örneğin; Tablo 18 ile gösterildiği gibi başlangıçta $50 \times 50$ boyutlu bir görüntü için hesaplanabilecek durumlardan bir kısmı aşağıdaki gibidir:

- filtre boyutu=3, filtre sayısı $=32$, kaydırma $\operatorname{ad} ı m ı=1$, havuzlama katman sayısı $=3$ ve evrişim katman sayısı $=3$ için evrişim işleminden sonra elde edilen $[4,6,32]$ boyutlu veri için düzleştirme işlemi 4x6×32=1×768 şeklinde yapılmakta ve bu tek boyutlu vektör tam bağlı katmana giriş verisi olarak verilmektedir.

- filtre boyutu=3, filtre sayısı $=20$, kaydırma $\operatorname{ad} ı \mathrm{~m}_{1}=3$, havuzlama katman sayısı $=2$ ve evrişim katman sayısı $=2$ için evrişim işleminden sonra elde edilen $[11,11,20]$ boyutlu veri düzleştirildiğinde $1 \times 2420$ boyutlu giriş verisi olarak tam bağlı katmana verilmektedir.

- filtre boyutu=3, filtre sayısı $=32$, kaydırma $\operatorname{ad} ı m_{1}=1$, havuzlama katman sayısı $=1$ ve evrişim katman sayısı $=1$ için evrişim işleminden sonra elde edilen [24,25,32] boyutlu veri düzleștirildiğinde $1 \times 19200$ boyutlu giriş verisi olarak tam bağlı katmana verilmektedir.

- filtre boyutu=4, filtre $\operatorname{say} 1 \mathrm{~s} 1=10$, kaydırma $\operatorname{ad} 1 \mathrm{~m} 1=2$, havuzlama katman sayısı $=2$ ve evrişim katman sayıs $=5$ için evrişim işleminden sonra elde edilen $[1,8,10]$ boyutlu veri düzleştirildiğinde 1 x80 boyutlu giriş verisi olarak tam bağlı katmana verilmektedir.

- filtre boyutu=7, filtre $\operatorname{say} 1 \mathrm{~s} 1=60$, kaydırma $\operatorname{ad} 1 \mathrm{~m} 1=1$, havuzlama katman sayısı $=3$ ve evrişim katman sayısı $=3$ için evrişim işleminden sonra elde edilen $[1,6,60]$ boyutlu veri düzleştirildiğinde $1 \times 360$ boyutlu giriş verisi olarak tam bağlı katmana verilmektedir.

filtre boyutu $=5$, filtre $\operatorname{say} 1 \mathrm{~s} 1=20$, kaydırma $\operatorname{ad} 1 \mathrm{~m} 1=5$, havuzlama katman sayısı $=1$ ve evrişim katman sayısı $=2$ için evrişim işleminden sonra elde edilen $[23,19,20]$ boyutlu veri düzleştirildiğinde 1 x8740 boyutlu giriş verisi olarak tam bağl1 katmana verilmektedir.

Tablo 18. Yeni Görüntü Boyutunun Hiper-parametre Değerlerine göre Değişimi (Table 18. Change of New Image Size according to Hyper-parameter Values)

\begin{tabular}{l|l|l|l|l|l|l|l}
\hline Durum & $\begin{array}{l}\text { Eski } \\
\text { Görüntü } \\
\text { Boyutu }\end{array}$ & $\begin{array}{l}\text { Filtre } \\
\text { Boyutu }\end{array}$ & $\begin{array}{l}\text { Filtre } \\
\text { Sayısı }\end{array}$ & $\begin{array}{l}\text { Kaydırma } \\
\text { Adımı }\end{array}$ & $\begin{array}{l}\text { Havuzlama } \\
\text { Katman } \\
\text { Sayısı }\end{array}$ & $\begin{array}{l}\text { Evrişim } \\
\text { Katman } \\
\text { Sayısı }\end{array}$ & $\begin{array}{l}\text { Yeni } \\
\text { Görüntü } \\
\text { Boyutu }\end{array}$ \\
\hline \hline & $50 \times 50$ & 3 & 32 & 1 & 3 & 3 & $1 \times 768$ \\
\hline 2 & $50 \times 50$ & 3 & 20 & 3 & 2 & 2 & $1 \times 2420$ \\
\hline 3 & $50 \times 50$ & 3 & 32 & 1 & 1 & 1 & $1 \times 2$ \\
\hline 4 & $50 \times 50$ & 4 & 10 & 2 & 2 & 5 & $1 \times 800$ \\
\hline 5 & $50 \times 50$ & 7 & 60 & 1 & 3 & 3 & $1 \times 360$ \\
\hline 6 & $50 \times 50$ & 5 & 20 & 5 & 1 & 2 & $1 \times 8740$ \\
\hline
\end{tabular}




\section{Sonuç}

Medikal görüntüler hastalıkların erken tanısında hayati öneme sahiptir. Medikal görüntülerin bir çeşidi olan patoloji görüntüleri, kanser başta olmak üzere hastalıkların kesin tanısında kullanılmaktadır. Patoloji görüntüleri; hastadan alınan şüpheli et, kan veya tükürük örneklerinin özel teknik ve makineler kullanılarak görselleştirilmesiyle elde edilmektedir. $\mathrm{Bu}$ çalışmada, kadınlarda en sık görülen hastalık olan meme kanserinin tanısı amaciyla meme patoloji görüntüleri sınıflandırılmıştır. 60000 görüntüden oluşan veri setinin, eşit sayıda kanserli ve kanserli olmayan görüntü içerecek şekilde 40000 tanesi eğitim ve 20000 tanesi test için ayrılmıştır.

Günümüzde sayısal veri üretebilen makinelerin ve internet kullanımının artması, çok büyük verilerin kaydedilebilmesini sağlamıştır. Bu büyük verileri işlemek için yetersiz kalan CPU işlemciler yerine daha büyük hesaplama kapasitelerine sahip GPU işlemcili makineler kullanılmaktadır. Bununla birlikte karmaşık işlemler yapan derin öğrenme yöntemleri, büyük verileri sınıflandırma ve tahmin etme işlemlerinde en çok tercih edilen yöntemlerdir.

Bu çalışmada, Google Colab platformunda NVIDIA TeslaK80 GPU işlemcili makine üzerinde açık kaynak kodlu Keras kütüphanesi ve Python programlama dili kullanılarak CNN mimarisi geliştirilmiştir.

Evrişim katmanlarındaki işlemler ile görüntü boyutları küçültülmekte ve evrişim işlemleri tamamlandıktan sonra elde edilen yeni boyutlu görüntü verileri düzleştirilerek tam bağlı yapay sinir ağına sunulmaktadır. Evrişim katmanlarında, görüntüler yeniden boyutlandırılırken filtre boyutu, filtre sayısı, kaydırma adımı, evrişim katman sayısı ve havuzlama katman sayısı hiper-parametreleri kullanılmaktadır.

Bu çalışmada geliştirilen derin öğrenme mimarisinin başarılı olabilmesi için filtre boyutu, filtre sayısı, kaydırma adımı, evrişim katman sayıs1, optimizasyon algoritmaları, eğitim tur sayısı, aynı anda işlenen görüntü sayısı (batch size) ve seyreltme değeri hiperparametreleri kullanılarak elde edilen sonuçlar karşılaştırılmıştır. Her hiper-parametre için mimari yeniden eğitilmiş ve test edilmiştir. Mimarinin eğitilmesi ve test edilmesi boyunca geçen süreler saniye cinsinden hesaplanmıştır. Filtre boyutu $3 \times 3$, filtre sayısı 32, kaydırma adımı 1, aynı anda işlenen görüntü sayısı 100, optimizasyon algoritması olarak RMSProp, seyreltme değeri 0.5 , eğitim tur sayısı 25 ve evrişim katman sayısı 3 değerleri kullanılarak tasarlanan mimarinin en başarılı sonuçları verdiği görülmüştür. Ayrıca gizli katmanlarda ReLU ve tam bağlı katmanda sigmoid fonksiyonu kullanılmıştır. Modelin başarısını ölçmek amacıyla kullanılan ve 1 değerine yakınsaması istenen doğruluk değeri 0.8775 , F1 skoru 0.8238 , hassasiyet değeri 0.8381 ve hatırlama değeri 0.8762 elde edilmiştir. Ayrıca 0 değerine yakınsaması istenen MSE değeri 0.1195 ve MAE değeri 0.2497 elde edilmiştir.

$\mathrm{Bu}$ çalışmada eğitim aşamasında, ağa aynı anda sunulan görüntü sayısının arttırılması ile öğrenme zamanının azalması sağlanmıştır. Ancak 100 değerinin üstüne çıkıldığında mimarinin başarısının düştüğü görülmüştür. Ağa aynı anda sunulan görüntü sayısı 1 olarak seçildiğinde ağın 4 saat çalışıp bellek hatası vererek durduğu gözlemlenmiştir. Ayrıca mimarinin konvolüsyon katman sayısı için 8 ve filtre boyutu için 8 değerleri seçildiğinde mimarinin eğitilemediği görülmüştür.
Mimarinin tam bağlı katmanlarında kullanılan sigmoid aktivasyon fonksiyonu softmax fonksiyonu ile karşılaştırılmış ve sigmoid fonksiyonu kullanıldığında 0.8775 doğruluk değeri elde edilirken softmax fonksiyonu kullanıldığında 0.4575 doğruluk elde edilmiştir.

Veri seti farklı oranlarda eğitim ve test setlerine ayrılarak mimariye sunulmuş ve elde edilen sonuçlar karşılaştırılmıştır. 52000 görüntü içeren eğitim seti, 8000 görüntü içeren test seti için mimarinin doğruluk değeri $0.7217 ; 54000$ görüntü içeren eğitim seti, 6000 görüntü içeren test seti için mimarinin doğruluk değeri 0.8 ve 56000 görüntü içeren eğitim seti, 4000 görüntü içeren test seti için mimarinin doğruluk değeri 0.73 elde edilmiştir. Ayrıca, daha düşük ve daha yüksek sayıda görüntü içeren meme patoloji veri setleri mimariye sunularak elde edilen sonuçlar karşılaştırılmıştır. 12000 görüntü içeren veri seti için doğruluk değeri $0.8,48000$ görüntü içeren veri seti için doğruluk değeri 0.78 ve 66000 görüntü içeren veri seti için doğruluk değeri 0.8167 olarak ölçülmüştür.

Elde edilen yüksek doğruluk, F1 skoru, hassasiyet ve hatırlama değerleri ile düşük hata değerleri, bu çalışma kapsamında önerilen $\mathrm{CNN}$ modelinin patoloji görüntülerinin sınıflandırılmasında kullanılabileceğini; özellikle tıp fakültelerinin ve hastanelerin patoloji bölümlerinde kullanılabilir sistemler tasarlanabileceğini göstermektedir. İlerideki çalışmalarda, hiper-parametre değerleri daha farklı ayarlanarak daha başarılı mimariler elde edilebilir. Ayrıca, derin öğrenme mimarilerinin daha farklı birçok alanda başarılı bir şekilde kullanılabileceği tahmin edilmektedir.

\section{Kaynakça}

Akkus, Z., Galimzianova, A., Hoogi, A., Rubin, D. L. ve Erickson, B. J. 2017. Deep learning for brain MRI segmentation: state of the art and future directions. Journal of digital imaging, 30:4, 449-459.

Alhussein, M. ve Muhammad, G. 2018. Voice Pathology Detection Using Deep Learning on Mobile Healthcare Framework. IEEE Access, 6, 41034-41041.

Alipanahi, B., Delong, A., Weirauch, M. T. ve Frey, B. J. 2015. Predicting the sequence specificities of DNA-and RNAbinding proteins by deep learning. Nature biotechnology, $33: 8,831$.

Anonim 2008. Biyomedikal cihaz teknolojileri Projesi) M M E v Ö S G (Ed.)

Anonim. 2019. Gradyan İniş Optimizasyon Algoritmalarına Genel https://devhunteryz.wordpress.com/2019/06/04/gradyaninis-optimizasyon-algoritmalarina-genel-bakis/. tarihi: 01.07.2019).

Basavanhally, A. 2010. Automated Image-Based Detection and Grading of Lymphocytic İnfiltration in Breast Cancer Histopathology. Rutgers University-Graduate School-New Brunswick, New Brunswick, New Jersey.

Basavanhally, A., Yu, E., Xu, J., Ganesan, S., Feldman, M., Tomaszewski, J. ve Madabhushi, A. (2011). Incorporating Domain Knowledge for Tubule Detection in Breast Histopathology Using O'Callaghan Neighborhoods. Medical Imaging 2011: Computer-Aided Diagnosis, International Society for Optics and Photonics, 1-13.

Bejnordi, B. E., Veta, M., Van Diest, P. J., Van Ginneken, B., Karssemeijer, N., Litjens, G., Van Der Laak, J. A., Hermsen, M., Manson, Q. F. ve Balkenhol, M. 2017. Diagnostic 
Assessment of Deep Learning Algorithms for Detection of Lymph Node Metastases in Women with Breast Cancer. Jama, 318:22, 2199-2210.

Belsare, A. ve Mushrif, M. 2012. Histopathological Image Analysis Using Image Processing Techniques: An Overview. Signal \& Image Processing: An International Journal (SIPIJ), 3:4, 23-33.

Cao, C., Liu, F., Tan, H., Song, D., Shu, W., Li, W., Zhou, Y., Bo, X. ve Xie, Z. 2018. Deep Learning and Its Applications in Biomedicine. Genomics, proteomics \& bioinformatics, 16, 17-32.

Carrio, A., Sampedro, C., Rodriguez-Ramos, A. ve Campoy, P. 2017. A review of deep learning methods and applications for unmanned aerial vehicles. Journal of Sensors, 2017.

Chen, H., Engkvist, O., Wang, Y., Olivecrona, M. ve Blaschke, T. 2018. The rise of deep learning in drug discovery. Drug discovery today.

Chen, H., Zhang, Y., Zhang, W., Liao, P., Li, K., Zhou, J. ve Wang, G. 2017a. Low-dose CT via convolutional neural network. Biomedical optics express, 8:2, 679-694.

Chen, L., Bentley, P. ve Rueckert, D. 2017b. Fully automatic acute ischemic lesion segmentation in DWI using convolutional neural networks. NeuroImage: Clinical, 15, 633-643.

Cireşan, D. C., Giusti, A., Gambardella, L. M. ve Schmidhuber, J. (2013). Mitosis Detection in Breast Cancer Histology Images with Deep Neural Networks. International Conference on Medical Image Computing and Computer-assisted Intervention, Springer, 411-418.

Cosatto, E., Miller, M., Graf, H. P. ve Meyer, J. S. (2008). Grading Nuclear Pleomorphism on Histological Micrographs. Pattern Recognition, 2008. ICPR 2008. 19th International Conference on, IEEE, 1-4.

Danaee, P., Ghaeini, R. ve Hendrix, D. A. (2017). A deep learning approach for cancer detection and relevant gene identification. PACIFIC SYMPOSIUM ON BIOCOMPUTING 2017, World Scientific, 219-229.

Das, D. K. ve Dutta, P. K. 2019. Efficient Automated Detection of Mitotic Cells From Breast Histological Images Using Deep Convolution Neutral Network with Wavelet Decomposed Patches. Computers in biology and medicine, 104, 29-42.

Davy, A., Havaei, M., Warde-Farley, D., Biard, A., Tran, L., Jodoin, P.-M., Courville, A., Larochelle, H., Pal, C. ve Bengio, Y. 2014. Brain Tumor Segmentation with Deep Neural Networks. 1-5.

Deniz, C. M., Xiang, S., Hallyburton, R. S., Welbeck, A., Babb, J. S., Honig, S., Cho, K. ve Chang, G. 2018. Segmentation of the proximal femur from MR images using deep convolutional neural networks. Scientific reports, 8:1, 16485.

Dinsmore, C. 2014. Survey of Neural Networks in Digital Pathology and Pathology Workflow. Thesis, DePaul University Department of Computing and Digital Media 6, Chicago, IL.

Ekmekji, A. 2016. Technical Report. Stanford University.

Fakoor, R., Ladhak, F., Nazi, A. ve Huber, M. (2013). Using deep learning to enhance cancer diagnosis and classification. Proceedings of the International Conference on Machine Learning, ACM New York, USA.

Fang, S.-H., Tsao, Y., Hsiao, M.-J., Chen, J.-Y., Lai, Y.-H., Lin, F.C. ve Wang, C.-T. 2018. Detection of Pathological Voice Using Cepstrum Vectors: A Deep Learning Approach. Journal of Voice. Fatakdawala, H., Xu, J., Basavanhally, A., Bhanot, G., Ganesan, S., Feldman, M., Tomaszewski, J. E. ve Madabhushi, A. 2010. Expectation-Maximization-Driven Geodesic Active Contour with Overlap Resolution (Emagacor): Application to
Lymphocyte Segmentation on Breast Cancer Histopathology. IEEE Transactions on Biomedical Engineering, 57:7, 16761689.

Fausett, L. V. 1994. Fundamentals of neural networks: architectures, algorithms, and applications. Prentice-Hall Englewood Cliffs, 3-88,

Fu, X., Liu, T., Xiong, Z., Smaill, B. H., Stiles, M. K. ve Zhao, J. 2018. Segmentation of Histological Images and Fibrosis Identification with a Convolutional Neural Network. Computers in biology and medicine, 98, 147-158.

Fukushima, K. ve Miyake, S. 1982. Competition and cooperation in neural nets. Springer, 267-285.

Gandomkar, Z., Brennan, P. C. ve Mello-Thoms, C. 2018. MuDeRN: Multi-category classification of breast histopathological image using deep residual networks. Artificial intelligence in medicine.

Gibson, E., Li, W., Sudre, C., Fidon, L., Shakir, D. I., Wang, G., Eaton-Rosen, Z., Gray, R., Doel, T. ve Hu, Y. 2018. NiftyNet: a deep-learning platform for medical imaging. Computer methods and programs in biomedicine, 158, 113-122.

Glotsos, D., Spyridonos, P., Cavouras, D., Ravazoula, P., Dadioti, P.-A. ve Nikiforidis, G. 2004. Automated segmentation of routinely hematoxylin-eosin-stained microscopic images by combining support vector machine clustering and active contour models. Analytical and quantitative cytology and histology, 26:6, 331-340.

Harorlı, D. H. ve Harorlı, O. T. 2012. Diş Hekimliğinde Görüntü Arşivleme ve İletişim Sistemleri. Atatürk Üniversitesi Diş Hekimliği Fakültesi Dergisi, 2012:3.

Havaei, M., Davy, A., Warde-Farley, D., Biard, A., Courville, A., Bengio, Y., Pal, C., Jodoin, P.-M. ve Larochelle, H. 2017. Brain Tumor Segmentation with Deep Neural Networks. Medical image analysis, 35, 18-31.

Hebb, D. O. 1949. The Organization of Behavior. John What \& Sons. Inc, 17-78, United States of America.

Hinton, G. E. (2007). Boltzmann Machines. Retrieved from Canada: https

://www.cs.toronto.edu/ hinton/csc321/readings/boltz321.pdf.

Hinton, G. E., Osindero, S. ve Teh, Y.-W. 2006. A fast learning algorithm for deep belief nets. Neural computation, 18:7, 15271554.

Hinton, G. E. ve Salakhutdinov, R. R. (2006). Reducing the dimensionality of data with neural networks (0036-8075). Retrieved from

Hopfield, J. J. 1982. Neural networks and physical systems with emergent collective computational abilities. Proceedings of the national academy of sciences, 79:8, 2554-2558.

İnik, Ö. ve Ülker, E. 2017. Derin Öğrenme ve Görüntü Analizinde Kullanılan Derin Öğrenme Modelleri. Gaziosmanpasa Journal of Scientific Research, 6, 85-104.

Isin, A. ve Ozdalili, S. 2017. Cardiac arrhythmia detection using deep learning. Procedia Computer Science, 120, 268-275.

Işık, G. ve Artuner, H. 2016. Radyo Sinyallerinin Derin Öğrenme Sinir Ağları ile Tanınması Recognition of Radio Signals with Deep Learning Neural Networks.

Ivakhnenko, A. G. e. ve Lapa, V. G. 1965. Cybernetic predicting devices. CCM Information Corporation.

İlkılıç Aytaç, Z., İşeri, İ. \& Dandıl, B. (2021). Derin Öğrenme Kullanarak Tiroid Kanseri Teşhisi. Avrupa Bilim ve Teknoloji Dergisi, (29), 292-298.

Janowczyk, A. ve Madabhushi, A. 2016. Deep Learning for Digital Pathology Image Analysis: A Comprehensive Tutorial with Selected Use Cases. Journal of pathology informatics, 7. 
Kaya, T. 2017. Radyografinin Temel Prensipleri ve Radyografik Yorumda Temel İlkeler.

Kaynar, O., Aydın, Z. ve Görmez, Y. 2017. Sentiment Analizinde Öznitelik Düşürme Yöntemlerinin Oto Kodlayıcılı Derin Öğrenme Makinaları ile Karşılaştırılması. Bilişim Teknolojileri Dergisi, 10:3, 319-326.

Kaynar, O., Görmez, Y. ve Işık, Y. E. (2016). Oto Kodlayici Tabanli Derİn Öğrenme Makİnalari İle Spam Tespìtİ. 3. Uluslararası Yönetim Bilişim Sistemleri Konferansı.

Keskenler, M. F. ve Keskenler, E. F. 2017. Geçmişten Günümüze Yapay Sinir Ağları ve Tarihçesi. Takvim-i Vekayi, 5:2, 8-18.

Khosravi, P., Kazemi, E., Imielinski, M., Elemento, O. ve Hajirasouliha, I. 2018. Deep convolutional neural networks enable discrimination of heterogeneous digital pathology images. EBioMedicine, 27, 317-328.

Kohl, M., Walz, C., Ludwig, F., Braunewell, S. ve Baust, M. (2018). Assessment of Breast Cancer Histology Using Densely Connected Convolutional Networks. International Conference Image Analysis and Recognition, Springer, 903-913.

Kohonen, T. 1982. Self-organized formation of topologically correct feature maps. Biological cybernetics, 43:1, 59-69.

Kolachalama, V. B., Singh, P., Lin, C. Q., Mun, D., Belghasem, M. E., Henderson, J. M., Francis, J. M., Salant, D. J. ve Chitalia, V. C. 2018. Association of pathological fibrosis with renal survival using deep neural networks. Kidney international reports, 3:2, 464-475.

Komura, D. ve Ishikawa, S. 2018. Machine Learning Methods for Histopathological Image Analysis. Computtational and Structural Biotechnology Journal, 16, 34-42.

Koyun, A. ve Afşin, E. Derin Öğrenme ile İki Boyutlu Optik Karakter Tanıma. Türkiye Bilişsim Vakfı Bilgisayar Bilimleri ve Mühendisliği Dergisi, 10:1, 11-14.

Krizhevsky, A., Sutskever, I. ve Hinton, G. E. (2012). Imagenet classification with deep convolutional neural networks. Advances in neural information processing systems, 1097-1105. Kvam, J. ve Kongsro, J. 2017. In vivo prediction of intramuscular fat using ultrasound and deep learning. Computers and Electronics in Agriculture, 142, 521-523.

LeCun, Y., Bengio, Y. ve Hinton, G. 2015. Deep learning. nature, 521:7553, 436-442.

LeCun, Y., Boser, B., Denker, J. S., Henderson, D., Howard, R. E., Hubbard, W. ve Jackel, L. D. 1989. Backpropagation applied to handwritten zip code recognition. Neural computation, 1:4, 541-551.

LeCun, Y., Bottou, L., Bengio, Y. ve Haffner, P. 1998. Gradientbased learning applied to document recognition. Proceedings of the IEEE, 86:11, 2278-2324.

Lee, C. S., Tyring, A. J., Deruyter, N. P., Wu, Y., Rokem, A. ve Lee, A. Y. 2017. Deep-learning based, automated segmentation of macular edema in optical coherence tomography. Biomedical optics express, 8:7, 3440-3448.

Li, H., Lin, Z., Shen, X., Brandt, J. ve Hua, G. (2015). A convolutional neural network cascade for face detection. Proceedings of the IEEE Conference on Computer Vision and Pattern Recognition, 5325-5334.

Lippmann, R. P. 1989. Pattern classification using neural networks. IEEE communications magazine, 27:11, 47-50.

Litjens, G., Kooi, T., Bejnordi, B. E., Setio, A. A. A., Ciompi, F., Ghafoorian, M., Van Der Laak, J. A., Van Ginneken, B. ve Sánchez, C. I. 2017. A Survey on Deep Learning in Medical Image Analysis. Medical image analysis, 42, 60-88.

Lo, S.-C. B., Chan, H.-P., Lin, J.-S., Li, H., Freedman, M. T. ve Mun, S. K. 1995. Artificial convolution neural network for medical image pattern recognition. Neural networks, 8:7-8, 1201-1214.

Madabhushi, A. ve Lee, G. 2016. Image analysis and machine learning in digital pathology: Challenges and opportunities: Elsevier.

McCulloch, W. S. ve Pitts, W. 1943. A logical calculus of the ideas immanent in nervous activity. The bulletin of mathematical biophysics, 5:4, 115-133.

Montavon, G., Samek, W. ve Müller, K.-R. 2018. Methods for interpreting and understanding deep neural networks. Digital Signal Processing, 73, 1-15.

Motlagh, N. H., Jannesary, M., Aboulkheyr, H., Khosravi, P., Elemento, O., Totonchi, M. ve Hajirasouliha, I. 2018. Breast Cancer Histopathological Image Classification: A Deep Learning Approach. bioRxiv, 242818.

Nedzved, A., Belotserkovsky, A., Lehmann, T. ve Ablameyko, S. (2007). Morphometrical Feature Extraction on Color Histological Images for Oncological Diagnostics. 5th International Conference on Biomedical Engineering, 379-384.

Nirschl, J. J., Janowczyk, A., Peyster, E. G., Frank, R., Margulies, K. B., Feldman, M. D. ve Madabhushi, A. 2017. Deep Learning for Medical Image Analysis. Elsevier, 179-195.

Özçelik, Y. B. \& Altan, A. (2021). Diyabetik Retinopati Teşhisi için Fundus Görüntülerinin Derin ÖğrenmeTabanlı Sinıflandırılması. Avrupa Bilim ve Teknoloji Dergisi, (29), 156167.

Pantanowitz, L. (2010). Digital images and the future of digital pathology. Journal of pathology informatics, Omaha, Nebraska.

Paramanandam, M., O’Byrne, M., Ghosh, B., Mammen, J. J., Manipadam, M. T., Thamburaj, R. ve Pakrashi, V. 2016. Automated segmentation of nuclei in breast cancer histopathology images. PloS one, 11:9, e0162053.

Pişkin, M. 2017. TensorFlow ile Sınıflandırıcı Eğitimi ve Görüntü Siniflandirma.

Poostchi, M., Silamut, K., Maude, R. J., Jaeger, S. ve Thoma, G. 2018. Image analysis and machine learning for detecting malaria. Translational Research, 194, 36-55.

Rani, R. U. ve Amsini, P. 2018. Image Processing Techniques Used In Digital Pathology Imaging: An Overview International Journal of Engineering Research in Computer Science and Engineering (IJERCSE), 5:1, 1-4.

Rende, F. Ş., Bütün, G. ve Karahan, Ş. 2017. Derin Öğrenme Algoritmalarında Model Testleri: Derin Testler. 10. Ulusal Yazılım Mühendisliği Sempozyumu 54-59.

Rosenblatt, F. 1958. The perceptron: a probabilistic model for information storage and organization in the brain. Psychological review, 65:6, 386 .

Roy, K., Banik, D., Bhattacharjee, D. ve Nasipuri, M. 2019. Patch-Based System for Classification of Breast Histology Images Using Deep Learning. Computerized Medical Imaging and Graphics, 71, 90-103.

Rumelhart, D. E., Hinton, G. E. ve Williams, R. J. 1986. Learning representations by back-propagating errors. nature, 323:6088, 533-535.

Sabeena, B. K., Nair, M. S. ve Bindu, G. 2018. Automatic Mitosis Detection in Breast Histopathology Images Using Convolutional Neural Network Based Deep Transfer Learning. Biocybernetics and Biomedical Engineering.

Saha, M., Chakraborty, C. ve Racoceanu, D. 2018. Efficient Deep Learning Model for Mitosis Detection Using Breast Histopathology Images. Computerized Medical Imaging and Graphics, 64, 29-40. 
Samala, R. K., Chan, H.-P., Hadjiiski, L. M., Cha, K. ve Helvie, M. A. (2016). Deep-learning convolution neural network for computer-aided detection of microcalcifications in digital breast tomosynthesis. Medical Imaging 2016: Computer-Aided Diagnosis, International Society for Optics and Photonics, 97850Y.

Sarıtaş, M. Z. 2015. Adli tıp uygulamalarında 3D (üç boyutlu) teknolojinin kullanımı.

Schirrmeister, R., Gemein, L., Eggensperger, K., Hutter, F. ve Ball, T. (2017). Deep Learning with Convolutional Neural Networks for Decoding and Visualization of EEG Pathology. Signal Processing in Medicine and Biology Symposium (SPMB), 2017 IEEE, IEEE, 1-7.

Sengur, A. (2016). Derin Aşırı Öğrenme Makinesi ile Yüz Tanıma.

Srivastava, N., Hinton, G., Krizhevsky, A., Sutskever, I. ve Salakhutdinov, R. 2014. Dropout: a simple way to prevent neural networks from overfitting. The Journal of Machine Learning Research, 15:1, 1929-1958.

Szegedy, C., Liu, W., Jia, Y., Sermanet, P., Reed, S., Anguelov, D., Erhan, D., Vanhoucke, V. ve Rabinovich, A. (2015). Going deeper with convolutions. Proceedings of the IEEE conference on computer vision and pattern recognition, 1-9.

Şeker, A., Diri, B. ve Balık, H. H. 2017. Derin Öğrenme Yöntemleri ve Uygulamaları Hakkında Bir İnceleme. Gazi Mühendislik Bilimleri Dergisi, 3:3, 47-64.

Tanyıldızı, E. ve Okur, S. 2016. Retina Görüntülerindeki Kan Damarlarının Belirlenmesi. Fırat Üniversitesi Mühendislik Bilimleri Dergisi, 28:2.

Trebeschi, S., van Griethuysen, J. J., Lambregts, D. M., Lahaye, M. J., Parmer, C., Bakers, F. C., Peters, N. H., Beets-Tan, R. G. ve Aerts, H. J. 2017. Deep learning for fully-automated localization and segmentation of rectal cancer on multiparametric MR. Scientific reports, 7:1, 5301.

Turan, M., Almalioglu, Y., Araujo, H., Konukoglu, E. ve Sitti, M. 2018. Deep endovo: A recurrent convolutional neural network (rcnn) based visual odometry approach for endoscopic capsule robots. Neurocomputing, 275, 1861-1870.

Vargas, R., Mosavi, A. ve Ruiz, L. 2017. Deep Learning: A Review. Advances in Intelligent Systems and Computing, 5:2.

Veta, M., Pluim, J. P., Van Diest, P. J. ve Viergever, M. A. 2014. Breast cancer histopathology image analysis: A review. IEEE Transactions on Biomedical Engineering, 61:5, 1400-1411.

Vieira, S., Pinaya, W. H. ve Mechelli, A. 2017. Using deep learning to investigate the neuroimaging correlates of psychiatric and neurological disorders: Methods and applications. Neuroscience \& Biobehavioral Reviews, 74, 5875.

Widrow, B. ve Hoff, M. E. (1960). Adaptive switching circuits. Retrieved from

World Health Organization. (2020). Breast Cancer. 12 Ekim 2021 tarihinde https://www.who.int/news-room/factsheets/detail/breast-cancer adresinden erişildi.

Xiao, K., Wang, Z., Xu, T. ve Wan, T. 2017. A Deep Learnıng Method For Detectıng And Classifyıng Breast Cancer Metastases In Lymph Nodes On Histopathological Images.

Xie, D., Zhang, L. ve Bai, L. 2017. Deep learning in visual computing and signal processing. Applied Computational Intelligence and Soft Computing, 2017.

Xu, J., Janowczyk, A., Chandran, S. ve Madabhushi, A. (2010). A Weighted Mean Shift, Normalized Cuts Initialized Color Gradient Based Geodesic Active Contour Model: Applications to Histopathology Image Segmentation. Medical Imaging 2010:
Image Processing, International Society for Optics and Photonics, 1-11.

Xu, J., Janowczyk, A., Chandran, S. ve Madabhushi, A. 2011. A High-Throughput Active Contour Scheme for Segmentation of Histopathological Imagery. Medical image analysis, 15:6, 851862.

Xu, Y., Jia, Z., Wang, L.-B., Ai, Y., Zhang, F., Lai, M., Eric, I. ve Chang, C. 2017. Large scale tissue histopathology image classification, segmentation, and visualization via deep convolutional activation features. BMC bioinformatics, 18:1, 281.

Yalçin, N., Alver, S. ve Uluhatun, N. (2018). Classification of Retinal Images with Deep Learning for Early Detection of Diabetic Retinopathy Disease. 2018 26th Signal Processing and Communications Applications Conference (SIU), IEEE, 1-4.

Yonekura, A., Kawanaka, H., Prasath, V. S., Aronow, B. J. ve Takase, H. (2017). Glioblastoma Multiforme Tissue Histopathology Images Based Disease Stage Classification with Deep CNN. Informatics, Electronics and Vision \& 2017 7th International Symposium in Computational Medical and Health Technology (ICIEV-ISCMHT), 2017 6th International Conference on, IEEE, 1-5.

Zhao, X., Wu, Y., Song, G., Li, Z., Zhang, Y. ve Fan, Y. 2018. A deep learning model integrating FCNNs and CRFs for brain tumor segmentation. Medical image analysis, 43, 98-111. 